OAK RIDGE

NATIONAL LABORATORY

MANAGED BY UT-BATTELLE

FOR THE DEPARTMENT OF ENERGY

\title{
Quarterly Progress Report for the Chemical and Energy Research Section of the Chemical Technology Division: April-June 1999
}

R. T. Jubin 

Chemical Technology Division

\author{
QUARTERLY PROGRESS REPORT FOR THE \\ CHEMICAL AND ENERGY RESEARCH SECTION OF \\ THE CHEMICAL TECHNOLOGY DIVISION: \\ APRIL-JUNE 1999
}

R. T. Jubin

Date Published-April 2000

\author{
Prepared by the \\ OAK RIDGE NATIONAL LABORATORY \\ Oak Ridge, Tennessee 37831-6285 \\ managed by \\ UT-BATTELLE, LLC \\ for the \\ U.S. DEPARTMENT OF ENERGY \\ under contract DE-AC05-00OR22725
}





\section{CONTENTS}

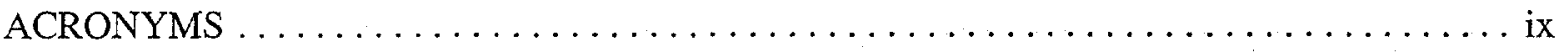

EXECUTIVE SUMMARY $\ldots \ldots \ldots \ldots \ldots \ldots \ldots \ldots \ldots \ldots \ldots \ldots \ldots \ldots \ldots \ldots \ldots$

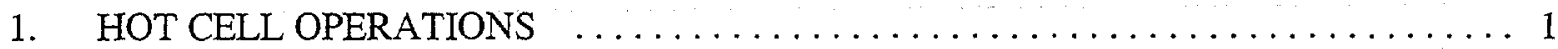

1.1 CESIUM REMOVAL USING CST IN SUPPORT OF THE MELTON

VALIEY WASTE TRIAD PROJECT $\ldots \ldots \ldots \ldots \ldots \ldots \ldots \ldots \ldots \ldots$

1.2 TESTING TWO CSTRS IN SERIES FOR THE SAVANNAH RIVER

SMALL-TANK TPB PRECIPITATION SIMULATION . . . . . . . . . . 1

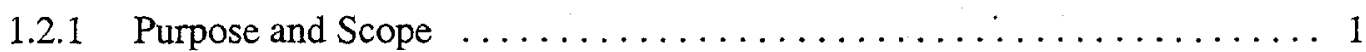

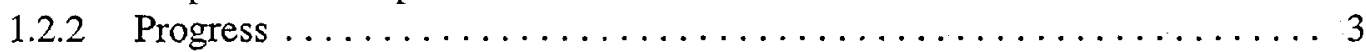

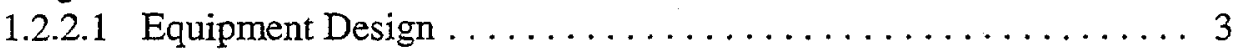

1.2.2.2 Materials .......................... 4

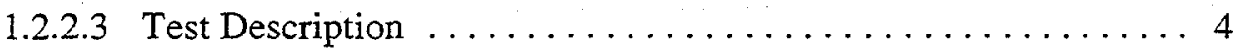

1.2.2.4 Operation During Test $1 \mathrm{~A} \ldots \ldots \ldots \ldots \ldots \ldots \ldots \ldots \ldots$

2. PROCESS CHEMISTRY AND THERMODYNAMICS $\ldots \ldots \ldots \ldots \ldots \ldots \ldots \ldots \ldots 7$

2.1 PREVENTION OF SOLIDS FORMATION $\ldots \ldots \ldots \ldots \ldots \ldots \ldots \ldots \ldots \ldots$

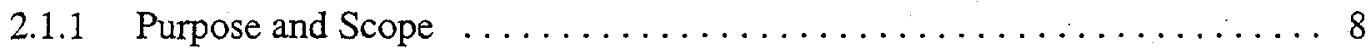

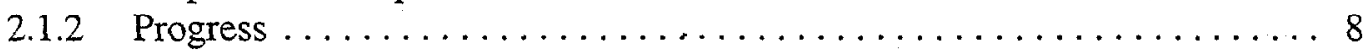

2.1.2.1 Viscosity Tests of Chemical Components in the Hanford

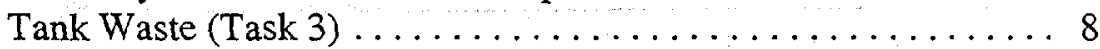

2.1.2.2 University Contest on Methods to Unplug a Plugged Transfer

Line (Task 4) ......................... 9

2.1.2.3 Operating Envelopes (Task 4) $\ldots \ldots \ldots \ldots \ldots \ldots \ldots \ldots$

2.1 .3 Publication .......................... 10

3. MSRE REMEDIATION STUDIES $\ldots \ldots \ldots \ldots \ldots \ldots \ldots \ldots \ldots \ldots \ldots \ldots \ldots \ldots$

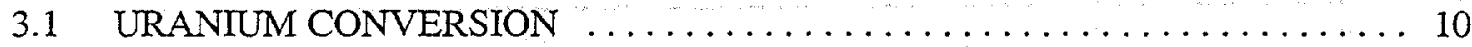

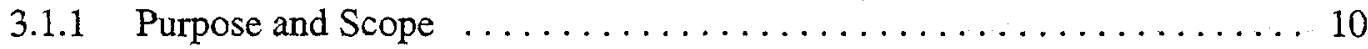

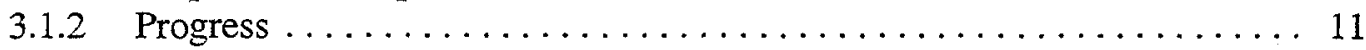

3.2 RADIOLYSIS AND MATERIALS DISPOSITION STUDIES $\ldots \ldots \ldots \ldots \ldots 11$

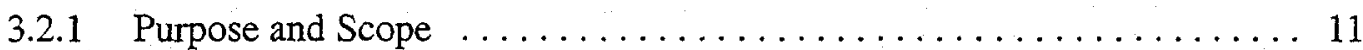

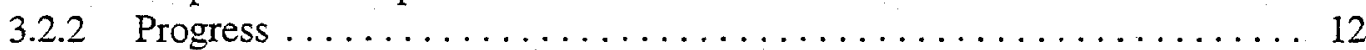

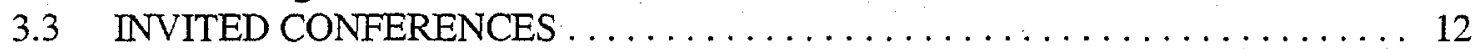

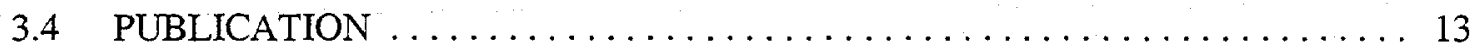

4. CHEMISTRY RESEARCH $\ldots \ldots \ldots \ldots \ldots \ldots \ldots \ldots \ldots \ldots \ldots \ldots \ldots \ldots \ldots$

4.1 MOLECULAR IMPRINTING ON SOL-GEL MATRICES $\ldots \ldots \ldots \ldots \ldots \ldots \ldots$

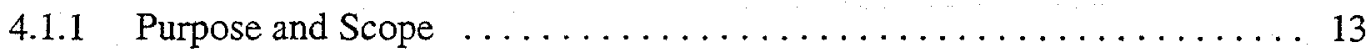

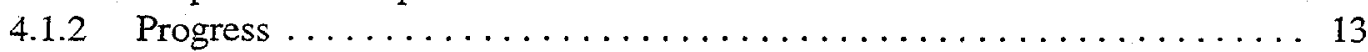

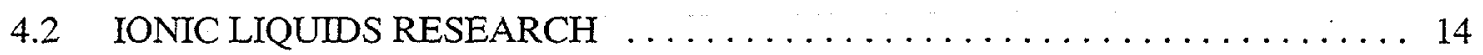

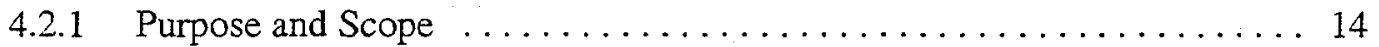

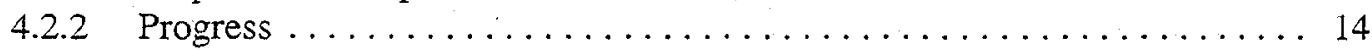




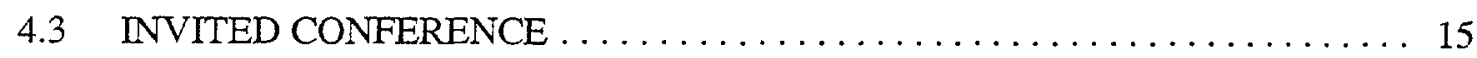

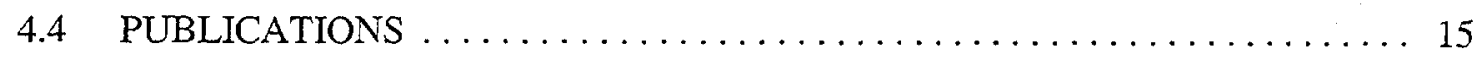

5. SEPARATIONS AND MATERIALS SYNTHESIS $\ldots \ldots \ldots \ldots \ldots \ldots \ldots \ldots \ldots$

5.1 CHEMICAL AND PHYSICAL PRINCIPLES IN MULTIPHASE

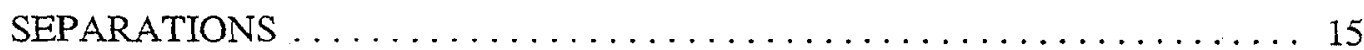

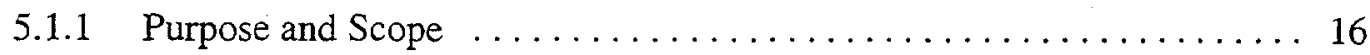

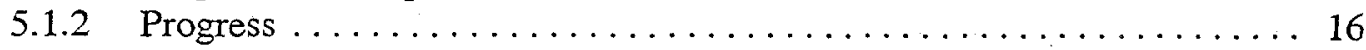

5.1.2.1 Electrohydrodynamic Spraying and Mixing $\ldots \ldots \ldots \ldots \ldots 16$

5.1.2.2 Nonlinear Bubble Production . . . . . . . . . . . . . 16

5.1 .2 .3 Gas-Liquid Hydrodynamics $\ldots \ldots \ldots \ldots \ldots \ldots \ldots \ldots \ldots \ldots \ldots$

5.1.2.4 Particle Interactions Under Magnetic Fields $\ldots \ldots \ldots \ldots \ldots 17$

5.2 NUCLEATION, GROWTH, AND TRANSPORT PHENOMENA $\ldots \ldots \ldots \ldots .17$

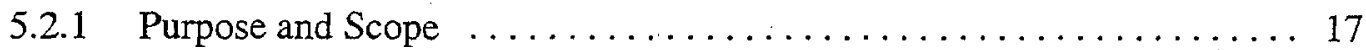

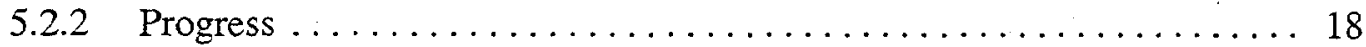

5.3 PHASE EQUILIBRIA MODIFICATION BY ELECTRIC FIELDS . . . . . . . . . 19

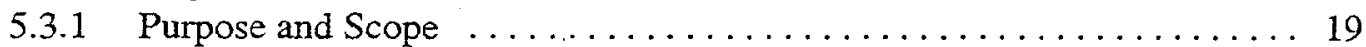

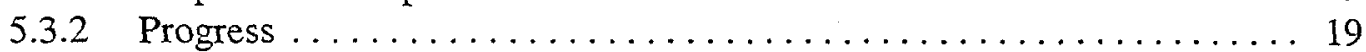

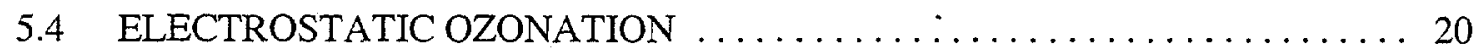

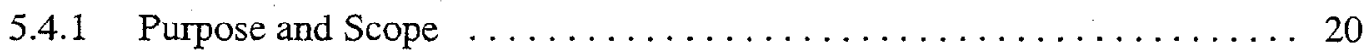

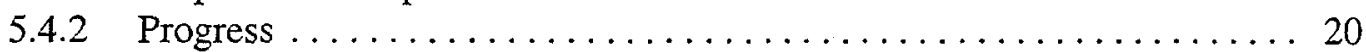

5.5 OZONE TREATMENT OF SOLUBLE ORGANICS IN PRODUCED WATER . 21

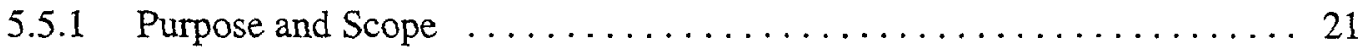

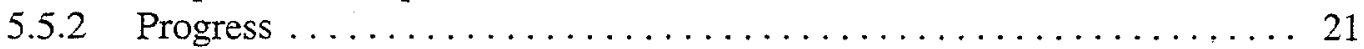

5.6 ELECTRICALLY DRIVEN TECHNOLOGIES FOR RADIOACTIVE

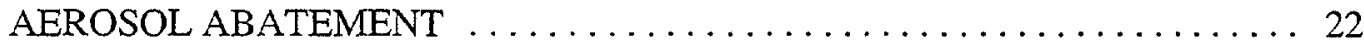

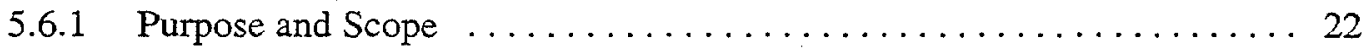

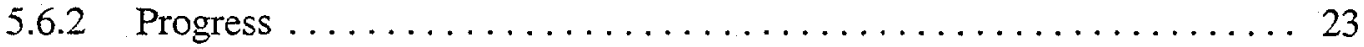

5.7 IMPROVED DECONTAMINATION: INTERFACIAL, TRANSPORT, AND CHEMICAL PROPERTIES OF AQUEOUS SURFACTANT CLEANERS . . . . 23

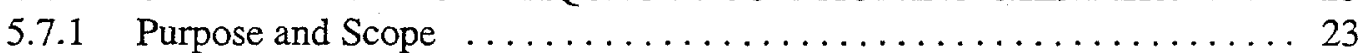

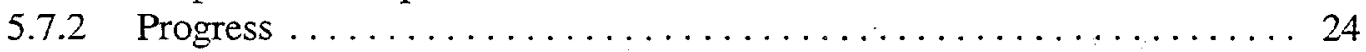

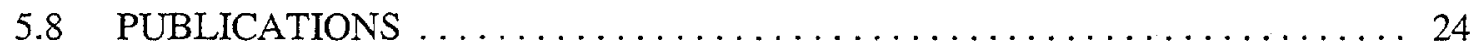

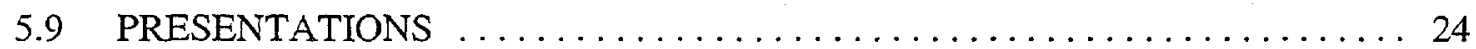

6. FLUID STRUCTURE AND PROPERTIES $\ldots \ldots \ldots \ldots \ldots \ldots \ldots \ldots \ldots \ldots \ldots$

6.1 INTERACTIONS OF SOLUTES, SOLVENTS, AND SURFACES $\ldots \ldots \ldots 25$

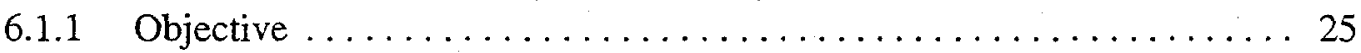

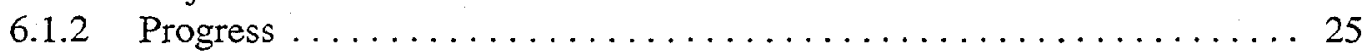


6.2 MOLECULAR-BASED STUDY OF REVERSE MICELLES IN

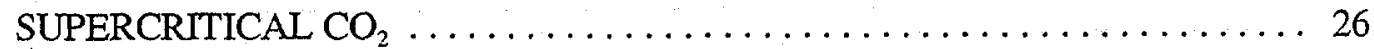

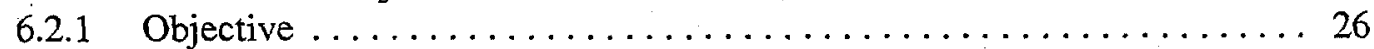

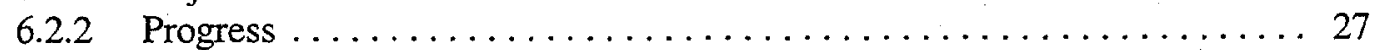

6.3 STRUCTURE AND PROPERTIES OF CHAIN MOLECULE

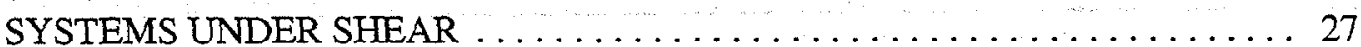

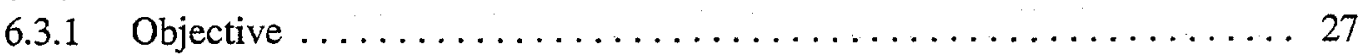

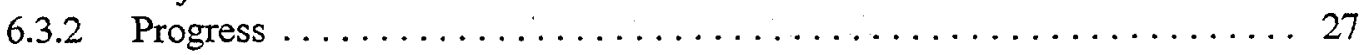

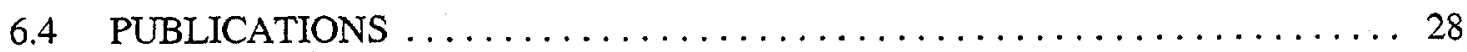

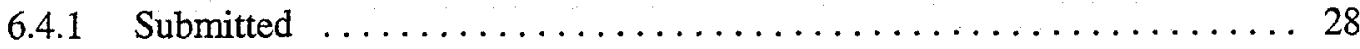

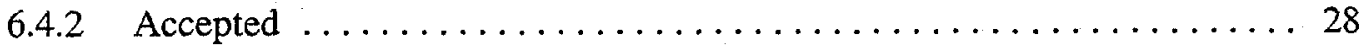

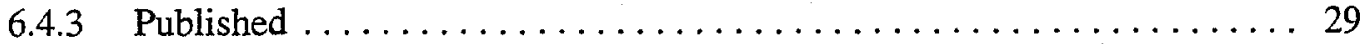

7. BIOTECHNOLOGY RESEARCH ................................. 29

7.1 KINETICS OF ENZYME-CATALYZED REACTIONS $\ldots \ldots \ldots \ldots \ldots \ldots \ldots 29$

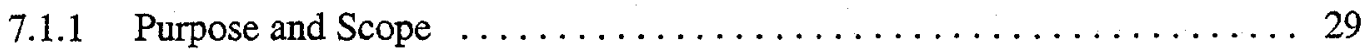

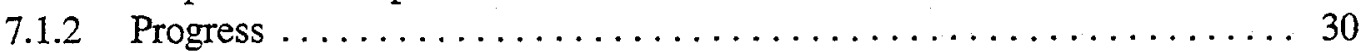

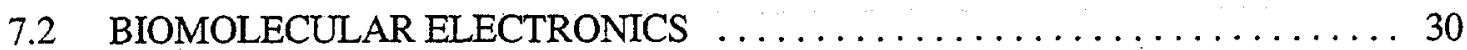

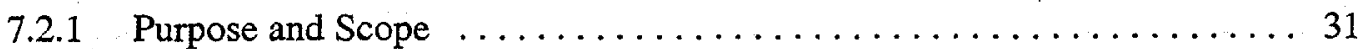

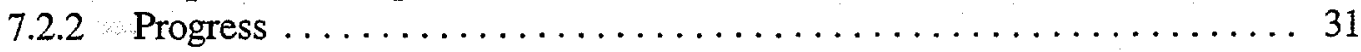

7.3 RENEWABLE HYDROGEN PRODUCTION BY PHOTOSYNTHETIC

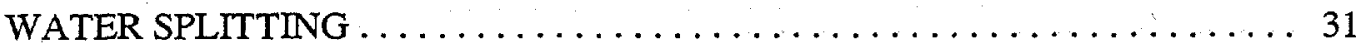

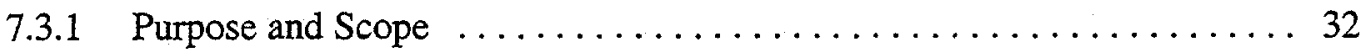

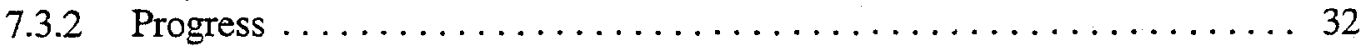

7.4 FLUOROMETRIC TISSUE-BASED BIOSENSORS $\ldots \ldots \ldots \ldots \ldots \ldots \ldots \ldots \ldots$

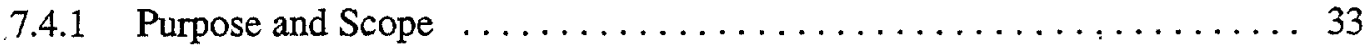

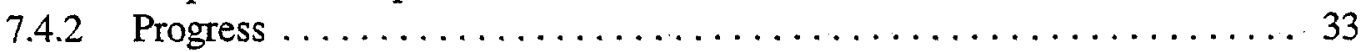

7.5 CELLULASES WITH ENHANCED ACTIVITY $\ldots \ldots \ldots \ldots \ldots \ldots \ldots \ldots \ldots \ldots$

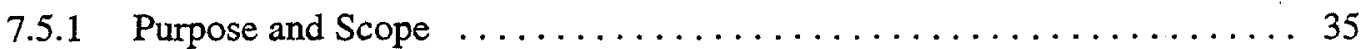

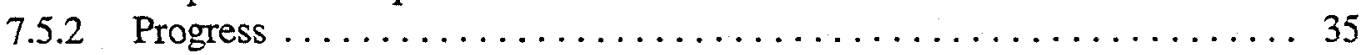

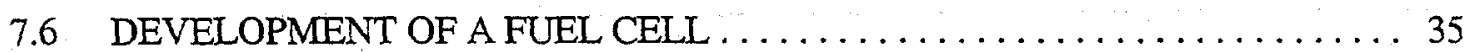

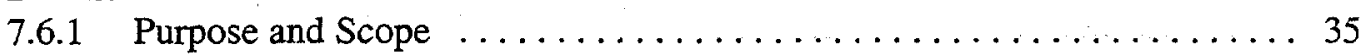

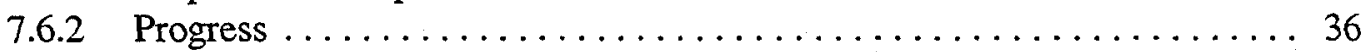

7.7 HYDROGEN PRODUCTION FROM RENEWABLES $\ldots \ldots \ldots \ldots \ldots \ldots \ldots . \ldots \ldots$

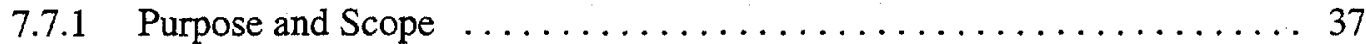

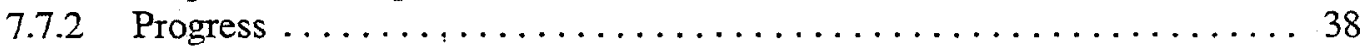

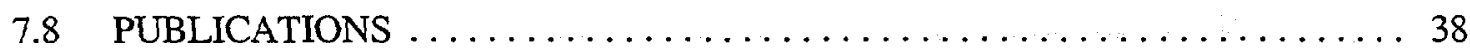

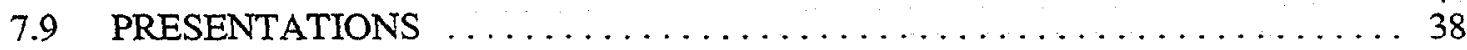




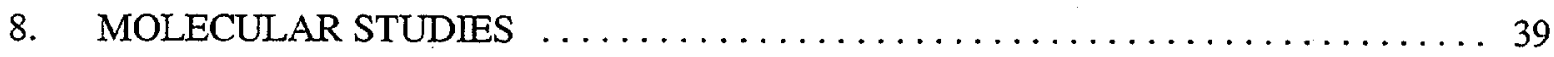

8.1 AQUEOUS ELECTROLYTE SOLUTIONS AT AMBIENT AND

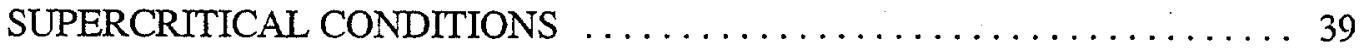

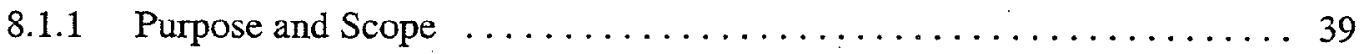

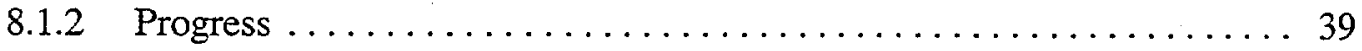

8.2 THEORY AND MOLECULAR SIMULATION OF NONEQUTLIBRIUM

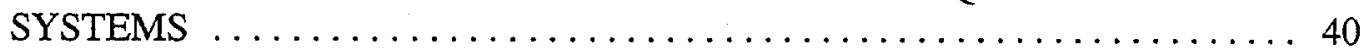

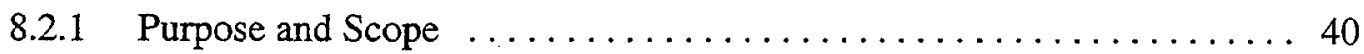

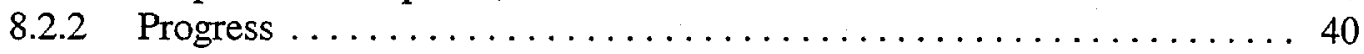

8.3 INTEGRAL EQUATION THEORIES OF MOLECULAR FLUIDS $\ldots \ldots \ldots \ldots 40$

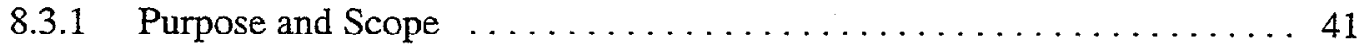

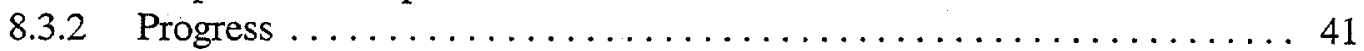

8.4 MATHEMATICAL MODELING OF BACTERIAL MIGRATION THROUGH POROUS MEDIA WITH APPLICATION TO IN SITU BIOREMEDIATION . . . 41

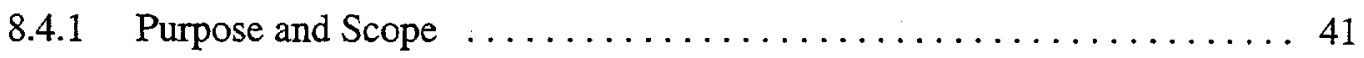

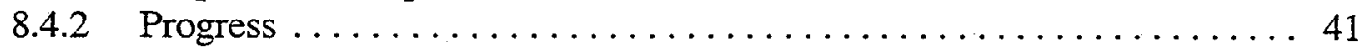

8.5 FUNDAMENTAL CHEMISTRY AND THERMODYNAMICS OF HYDROTHERMAL OXIDATION PROCESSES $\ldots \ldots \ldots \ldots \ldots \ldots \ldots \ldots . \ldots 2$

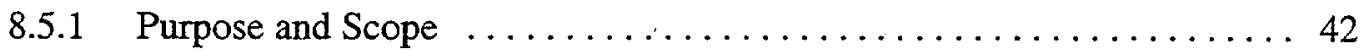

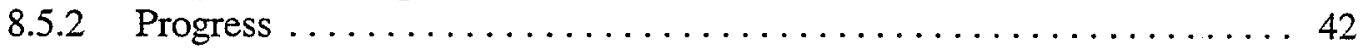

8.6 DEVELOPMENT AND APPLICATION OF FAST COMPUTATIONAL PROTEIN-FOLDING ALGORITHMS USING MASSIVELY PARALLEL

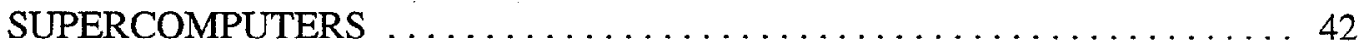

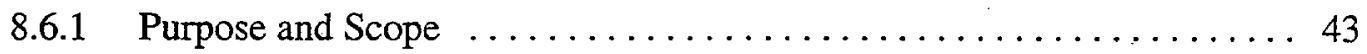

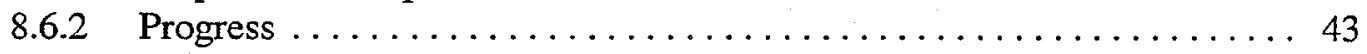

8.7 MOLECULAR-BASED STUDY OF REVERSE MICELLES IN

SUPERCRITICAL CARBON DIOXIDE FOR SOLVENT SUBSTITUTION

IN THE U.S. CHEMICAL INDUSTRY $\ldots \ldots \ldots \ldots \ldots \ldots \ldots \ldots \ldots \ldots \ldots 43$

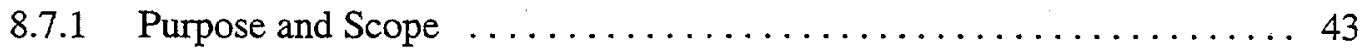

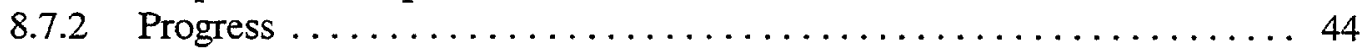

8.8 NANOTECHNOLOGY WTH EMPHASIS ON TRIBOLOGY: A COMBINED EXPERIMENTAL AND SIMULATION STUDY $\ldots \ldots \ldots \ldots \ldots \ldots \ldots \ldots 44$

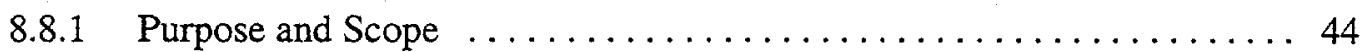

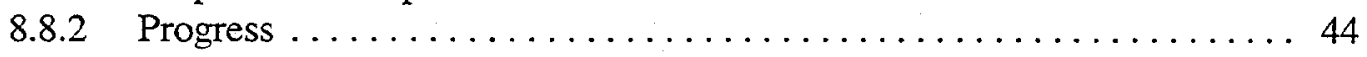

8.9 OTHER IMPORTANT ACTIVITIES $\ldots \ldots \ldots \ldots \ldots \ldots \ldots \ldots \ldots$

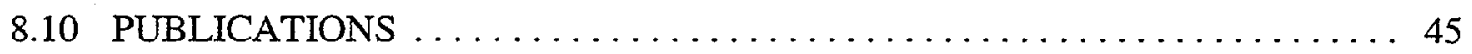

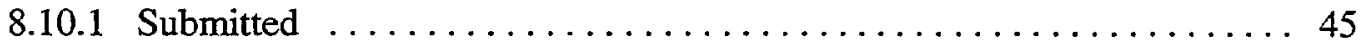

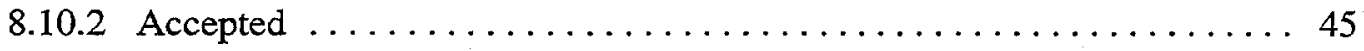

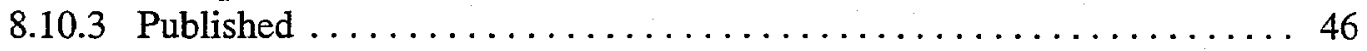




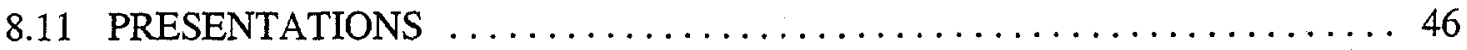

8.11 .1 Invited Seminars $\ldots \ldots \ldots \ldots \ldots \ldots \ldots \ldots \ldots \ldots \ldots \ldots, 46$

8.11 .2 Invited Conference $\ldots \ldots \ldots \ldots \ldots \ldots \ldots \ldots \ldots \ldots \ldots \ldots, 46$ 



\section{ACRONYMS}

$\begin{array}{ll}\text { ACB } & \text { auxiliary charcoal bed } \\ \text { AFM } & \text { atomic force microscopy } \\ \text { CTAB } & \text { cetyltrimethylammonium bromide } \\ \text { CBD } & \text { cellulose-binding domain } \\ \text { CST } & \text { crystalline silicotitanate } \\ \text { CSTR } & \text { continuously stirred tank reactor } \\ \text { DBS } & \text { dibutyl sulfide } \\ \text { DF } & \text { decontamination factor } \\ \text { DLS } & \text { dynamic light scattering } \\ \text { DOE } & \text { U.S. Department of Energy } \\ \text { DTA } & \text { differential thermal analysis } \\ \text { DTS } & \text { dielectric tuning solution } \\ \text { EHD } & \text { electrohydrodynamic } \\ \text { FTIR } & \text { Fourier transform infrared } \\ \text { GDH } & \text { glucose dehydrogenase } \\ \text { HFIR } & \text { High Flux Isotope Reactor } \\ \text { HLW } & \text { high-level waste } \\ \text { HPLC } & \text { high-performance liquid chromatography } \\ \text { ICP-AE } & \text { inductively coupled plasma-atomic emission } \\ \text { MSRE } & \text { Molten Salt Reactor Experiment } \\ \text { MST } & \text { monosodium titanate } \\ \text { NADP } & \text { nicotinamide adenine dinucleotide phosphate } \\ \text { NaTPB } & \text { sodium tetraphenylborate } \\ \text { ORNL } & \text { Oak Ridge National Laboratory } \\ \text { PCPA } & \text { parallel-corrugated-plate apparatus } \\ \text { PEG } & \text { polyethylene glycol } \\ \text { PLL } & \text { poly-L-lysine } \\ \text { SALS } & \text { small-angle light scattering } \\ \text { SANS } & \text { small-angle neutron scattering } \\ \text { SAXS } & \text { small-angle X-ray scattering } \\ \text { SRS } & \text { Savannah River Site } \\ \text { SRTC } & \text { Savannah River Technology Center } \\ \text { TBA } & \text { tributylamine } \\ \text { TFA } & \text { Tanks Focus Area } \\ \text { TGA } & \text { thermogravimetric analysis } \\ \text { TMOS } & \text { tetramethylorthosilicate } \\ \text { TPB } & \text { tetraphenylborate } \\ \text { TSPBC } & \text { N-trimethoxysilylpropyl-N,N,N-tri- } n \text {-butylammonium chloride } \\ \text { TSPGC } & \text { 1-trimethoxysilylpropyl-3-guanidine chloride } \\ \text { TSPMC } & \text { N-trimethoxysilylpropyl-N,N,N-trimethylammonium chloride } \\ \text { TTCF } & \text { transient time correlation function } \\ \text { TWRS } & \text { Tank Waste Remediation System } \\ \text { WAC } & \text { waste acceptance criteria } \\ \text { XRD } & \text { X-ray diffraction } \\ & \\ & \end{array}$





\section{EXECUTIVE SUMMARY}

This report summarizes the major activities conducted in the Chemical and Energy Research Section of the Chemical Technology Division at Oak Ridge National Laboratory (ORNL) during the period April-June 1999. The section conducts basic and applied research and development in chemical engineering, applied chemistry, and bioprocessing, with an emphasis on energy-driven technologies and advanced chemical separations for nuclear and waste applications.

The report describes the various tasks performed within eight major areas of research: Hot Cell Operations, Process Chemistry and Thermodynamics, Molten Salt Reactor Experiment (MSRE) Remediation Studies, Chemistry Research, Separations and Materials Synthesis, Fluid Structure and Properties, Biotechnology Research, and Molecular Studies. The name of a technical contact is included with each task described, and readers are encouraged to contact these individuals if they need additional information.

Activities conducted within the area of Hot Cell Operations involved the installation and plans for testing of a continuously stirred tank reactor system to evaluate the Savannah River-developed process of small-tank tetraphenylborate precipitation to remove cesium, strontium, and transuranics from supernatant.

Within the area of Process Chemistry and Thermodynamics, various topics related to solids formation in process solutions from caustic treatment of Hanford sludge were addressed: viscosity measurements, removal of pipeline plugs; and development of operating parameters to prevent such plugs.

MSRE Remediation Studies focused on recovery of ${ }^{233} \mathrm{U}$ and its transformation into a stable oxide and radiolysis experiments to permit remediation of MSRE fuel salt.

In the area of Chemistry Research, activities included studies relative to molecular imprinting for use in areas such as selective sorption; chemical sensing, and catalysis, as well as spectroscopic investigation into the fundamental interaction between ionic solvents and solutes in both low- and high-temperature ionic liquids.

In the area of Separations and Materials Synthesis, fundamental studies explored the use of electromagnetic fields to enhance transport processes in multiphase separations; investigated nucleation and particle growth for the synthesis, characterization, application, and processing of ultrafine particles; and examined the use of electric fields to modify phase equilibria in multiphase separations processes. Other efforts involved enhanced oxidation of organic pollutants in aqueous solutions by applying electric fields to form microbubbles, the use of ozonation to treat water-soluble organics, the application of electrical and acoustic methods to remediate aerosol problems, and the development of improved means of decontamination using aqueous surfactant cleaners.

Fluid Structure and Properties included molecular-based studies of systems with supercritical solvents, a multi-institutional initiative to develop a molecular understanding of reverse miscelles in supercritical carbon dioxide through experimentation and molecular simulation calculations, and molecular-based prediction of the structure and properties of long-chain molecules undergoing shear flow. 
Within the area of Biotechnology Research, tasks included research into fundamental reactions of photosynthesis, development of molecular optoelectronic devices, investigation of renewable hydrogen production by photosynthetic water splitting, and utilization of microalgae as biosensors. In enzyme-related work, studies were undertaken to improve biocatalysts by increasing the catalytic rate of hydrolysis of cellulose and to increase the efficiency of enzymatic production of hydrogen from glucose. Research continued to focus as well on nonenzymatic production of hydrogen, specifically from an iron-powder catalyst. Molecular characterization of organisms that make up a commercial culture that affords protection from Salmonella contamination has been conducted, and an industrial partner is being sought for the second phase of the project.

In the final area-Molecular Studies - as part of an effort to enhance our microscopic-level understanding of aqueous electrolyte solutions, simulations of supercooled water were performed. The investigation of simulation algorithms for nonequilibrium systems continued, and the ChialvoCummings solvation formalism was applied to electrolyte solutions. Production runs were performed using the parallelized Geocore algorithm, and large-system runs were conducted of the simulation code for reverse miscelles. In addition, molecular simulations of perfluoroalkane systems were initiated, and molecular dynamics simulations of alkanes confined to nanoscale gaps were continued. 


\title{
1. HOT CELL OPERATIONS
}

\author{
E. C. Beahm
}

\subsection{CESIUM REMOVAL USING CST IN SUPPORT OF THE MELTON VALLEY WASTE TRIAD PROJECT (D. D. Lee and C. W. Chase)}

Contact: D. D. Lee

Telephone: (423) 576-2689

Internet: leedd@ornl.gov

Summary: No Melton Valley Storage Tank supernatants were tested during this reporting period in support of the Waste Triad Project in Melton Valley.

\subsection{TESTING TWO CSTRS IN SERIES FOR THE SAVANNAH RIVER SMALL-TANK TPB PRECIPITATION SIMULATION (D. D. Lee, J. L. Collins, and C. W. Chase)}

Contact: D. D. Lee

Telephone: (423) 576-2689

Internet: leedd@ornl.gov

Summary: One of the proposed methods of removing the cesium, strontium, and transuranics from the radioactive waste storage tanks at Savannah River is the small-tank tetraphenylborate (TPB) precipitation process. A continuously stirred tank reactor (CSTR) system (two reactors in series, each 15-L working volume) was designed, constructed, and installed in a hot cell to test the Savannah River-developed process. The system also includes two cross-flow filtration systems to concentrate and wash the slurry produced in the process, which contains the bulk of radioactivity from the supernatant processed through the system. Installation, operational readiness reviews, and system preparation and testing were completed. The first test using the system's two CSTRs and the slurry concentration system was conducted over a 61-h period with design removal of cesium, strontium, and uranium achieved.

\subsubsection{Purpose and Scope}

This section describes the planned testing at Oak Ridge National Laboratory (ORNL) to evaluate the decontamination achievable in the small-tank TPB precipitation process for the removal of cesium, strontium, and uranium from simulated Savannah River supernatant. It will also evaluate the catalytic decomposition of TPB during operation. The task is in support of the conceptual design phase for one of the selected alternatives to the High-Level Waste (HLW) Salt Disposition Project. As part of these tests, a CSTR system containing two CSTRs in series, each with a 15-L working volume, was designed. A precipitate concentration system (including a cross-flow filter), a precipitate wash system (with cross-flow filter), and various tanks and pumps to integrate the operations are included. Simulated waste supernatant, dilution water, recycle wash solution, sodium 
tetraphenylborate (NaTPB) solution, and monosodium titanate (MST) slurry will be fed to the first CSTR. Overflow from this CSTR will be passed into a second CSTR, which will then overflow to the third vessel, in which the slurry of precipitated potassium TPB, cesium TPB, excess NaTPB, sludge, and MST are concentrated. The filtrate from the slurry concentration step is the decontaminated product. The concentrated slurry will then be washed in a fourth vessel, and the washed solids will be stored as the HLW product. The wash solution will be recycled to the feed tank.

Information needed for the scaleup of the small-tank TPB precipitation process will be provided by these tests. Analyses to be performed during the operation of the process include highperformance liquid chromatography (HPLC) for $\mathrm{K}, \mathrm{Cs}, \mathrm{Cu}, \mathrm{B}, \mathrm{Pd}, \mathrm{Sr}$, and $\mathrm{U}$ to determine interstage conversion and demonstrate that the treated supernatant meets the required levels for waste acceptance criteria (WAC): $\mathrm{Cs},<70 \mathrm{nCi} / \mathrm{g}$; total alpha, $<18 \mathrm{nCi} / \mathrm{g}$; and $\mathrm{Sr},<40 \mathrm{nCi} / \mathrm{g}$. The desired levels of treatment-Cs, $<40 \mathrm{nCi} / \mathrm{g}$; alpha, $<10 \mathrm{nCi} / \mathrm{g}$; and $\mathrm{Sr},<20 \mathrm{nCi} / \mathrm{g}$-are set at $\sim 50 \%$ of the WAC to allow for changes in process conditions. In this set of experiments, the alpha analyses will be followed by analyzing uranium. The apparatus will be constructed of stainless steel, with the CSTR vessels having a minimum of four inlet tubes. The CSTRs and other process vessels will be purged with nitrogen gas as required, and the CSTRs and filter feed vessels will contain a cooling coil to maintain $\pm 2{ }^{\circ} \mathrm{C}$ temperature control. The first test will be performed without the addition of the enhanced catalyst components, copper and palladium catalysts that have been shown to cause the decomposition of the TPB, but sludge surrogate supplied by Savannah River will be added to the feed mixture. The precipitate washing system will not be used during the first test series; therefore, it will be performed with a simulated recycle stream. Test 1 will be divided into three phases (A, B, and C), with phases $B$ and $C$ to be conducted only if prior phases do not achieve the required decontamination factor (DF). Phase A will use the excess TPB and residence time defined by prior Savannah River Technology Center (SRTC) tests and provided by the Savannah River Site (SRS). If the DF goals are not met, the amount of excess TPB will be increased (Phase B), and if the DFs are still not obtained, the residence time in Phase $\mathrm{C}$ will be increased to achieve the goal.

Test 2 will examine the fully integrated flow sheet, which includes measurements of several parameters (including interstage conversions of cesium, strontium, and uranium) and evaluation of the catalytic decomposition of TPB by copper and palladium catalysts. A minimum of four system turnovers (defined by four turnovers of the wash and concentrate tanks) will be performed for the test. The required residence times for CSTRs will be based on data from Test 1 . 


\subsubsection{Progress}

\subsubsection{Equipment Design}

During this reporting period, the equipment was installed in hot cells $\mathrm{B}$ and $\mathrm{A}$ in Building 4501 at ORNL. The small-tank TPB precipitation pilot-scale system will use reactors with a 20-L total volume and a $15-\mathrm{L}$ working volume. The CSTRs were constructed from 316 stainless steel and have flanged tops with center, flange-mounted agitators. The agitator size is $1 / 4$ the CSTR internal diameter. Each reactor also includes four baffles, which are 1/12 the diameter of the tank and attached to the top flange. The vapor space of each CSTR is purged continuously with nitrogen gas during operation. The feed streams to the first CSTR (supernatant, MST/dilution water/NaTPB, and recycle wash water) enter through the top flange and discharge under the surface of the liquid in the CSTR near the agitator. The transfer lines from the reactors to the downstream vessel will also open at the liquid surface and exit through the side of the vessel, feeding the next vessel under the liquid surface in that vessel. The supernatant mixture in the CSTRs is internally cooled or heated by stainless steel cooling coils positioned below the working liquid level in the reactor.

The size of the vessel for concentrating the precipitate was changed during design reviews to be a 10-L-volume, 8-in.-diam vessel with a configuration similar to that of the CSTRs, with centermounted agitator and cooling coils. The working volume of the tank will be held constant as the concentration of solids in the precipitate increases during the filtration. The contents of the tank are pumped through a cross-flow filter using a progressive-cavity (Moyno) pump with a 316 stainless steel chrome-plated rotor and an ethylene-propylene-diene monomer (EPDM) stator. The slurry is returned to the vessel while the filtrate is sent to the product collection tank. The supernatant filtered product will be tested for the required DFs while the precipitate is being concentrated to about $10 \mathrm{wt} \%$ solids. After accumulating the desired volume of $10 \%$ solids, the slurry will be transferred to the precipitate wash vessel. The wash vessel is the same size and configuration as the precipitate concentration vessel but has a 5-L working volume. A second cross-flow filter is used to perform the precipitate washing step. The wash vessel is operated at constant volume with constant wash water feed and filtrate removal until the nitrite concentration is reduced to $0.01 M$ or less. The wash is used to remove excess salt and NaTPB for recycle to the system feed tank. The filtered wash liquid is sent to the recycle storage tank, and the washed solids will be transferred to the solids storage tank. The solids wash cycle requires about $24 \mathrm{~h}$.

Liquid and slurry feeds are transferred using small-volume gear and peristaltic pumps. The $10 \%$ solids slurries in the precipitate concentrate tank and the precipitate wash tank will be transferred using the Moyno pumps normally used for the cross-flow filter feed. To lessen potential 
radiation dose to workers should they have to enter the hot cell, the tanks for simulated supernatant feed waste and tracer addition were placed in the adjacent cell $\mathrm{A}$, and the connecting tubing and electrical controls were run through the wall between the cells.

The instrumentation and control strategy for the CSTR test system is based on controlling the two cross-flow filtration systems. The pressure on both sides of the filter is controlled using pressure-control valves. These control the transmembrane pressure, and as a result, control the filtrate flow rate. Parameters that will be monitored and recorded include temperature, pressure, liquid level, density, pump speed, agitator speed, and flow rates. Feedback-control systems will be used to control flow, level, and pressure. The control strategy for the process was reviewed and approved by SRS and Oak Ridge, and the Intellution ${ }^{\circ}$ control program was chosen for use.

\subsubsection{Materials}

The MST, catalyst makeup, and sludge used in these tests were supplied by SRS, and the supernatant simulants were prepared at ORNL using a recipe provided by SRS. Normal cesium and strontium traced with ${ }^{137} \mathrm{Cs}$ and ${ }^{85} \mathrm{Sr}$ will be used to obtain the needed concentration of cesium and strontium, and ${ }^{235} \mathrm{U}$ will be used as a stand-in for transuranic components in the simulated supernatant. In order to ensure the level of strontium added, the simulant was treated with MST and then filtered to remove strontium impurities present in some of the chemicals used to make up the feed. The amounts of tracers added are dictated by the counting accuracy that is required after the TPB precipitation. The amount of tracer required was about $1 \mathrm{Ci}$ of ${ }^{137} \mathrm{Cs}$ and $0.1 \mathrm{Ci}$ of ${ }^{85} \mathrm{Sr}$ for Test $1 \mathrm{~A}$, and no catalyst or sludge was used in Test $1 \mathrm{~A}$.

\subsubsection{Test Description}

CSTR sizes are 15,000-gal working volume. Assuming 20-L bench-scale vessels with $15-\mathrm{L}$ working volume, scales are $1 \mathrm{gal}=1 \mathrm{~mL}$ and $1 \mathrm{gal} / \mathrm{min}=1 \mathrm{~mL} / \mathrm{min}$. For the bench-scale system, the flow rates of the various feeds include the following:

1. salt feed-21.5 $\mathrm{mL} / \mathrm{min}$ at $6.4 \mathrm{MNa}^{+}$and $0.017 \mathrm{M} \mathrm{K}^{+}$;

2. dilution water plus MST ( $0.4 \mathrm{~g} \mathrm{MST/L}$ salt solution- $2.7 \mathrm{~mL} / \mathrm{min})$;

3. makeup NaTPB- $0.7 \mathrm{~mL} / \mathrm{min}$ at $0.55 \mathrm{M}$ TPB (stoichiometric-assumes no TPB decomposition);

4. recycle wash water- $6.8 \mathrm{~mL} / \mathrm{min}$ at $1.25 \mathrm{MNa}^{+}$and $0.03 \mathrm{MTPB}$-average (TPB-60\% excess);

5. total flow exiting the CSTRs- $31.7 \mathrm{~mL} / \mathrm{min}$ of $0.5 \mathrm{wt} \%$ slurry, residence time in each CSTR-8 h. 
The operating process will make about $1.2 \mathrm{~mL} / \mathrm{min}$ of $10 \mathrm{wt} \%$ unwashed slurry and $30.5 \mathrm{~mL} / \mathrm{min}$ of decontaminated salt solution with about 4.7 $M$ sodium. Experimental residence time for the CSTR for the first case is $t=8 \mathrm{~h}$. For the first series, the tests are expected to last for $60 \mathrm{~h}$ (more than seven residence times, or the time required for the production of one batch of precipitated concentrated solids) and make approximately 4-5 $\mathrm{L}$ of unwashed $10 \mathrm{wt} \%$ precipitate.

The 15-L CSTR system was prepared for startup by first preparing the feed mixture in cell A and then adding the final component, ${ }^{137} \mathrm{Cs}$. CSTRI was emptied of the cold-test solution and prepared to receive the feed mixture. Control operations testing of the concentration system using CSTR2, the concentrate vessel, and the filtration system was completed; and those components were then prepared to receive the simulated waste feed and dilution water as they eventually passed from CSTR1. Because it would require at least $8 \mathrm{~h}$ to fill CSTR1, this was accomplished while flow tests on CSTR2 and the concentration filter loop were completed.

The CSTR feed system was set up to pump the feed from the cell $\mathrm{A}$ feed tanks at the flow rate designed for the test, $21.5 \mathrm{~mL} / \mathrm{min}$, and pumped at about 21.5 to $22 \mathrm{~mL} / \mathrm{min}$ for the duration of Test 1A. Dilution water was used to produce the desired volume of material in the three vessels during the initial filling operation. Dilution water was the only material added with the waste feed during the startup stage and was fed in from outside of cell $\mathrm{B}$ using the recycle wash water feed pump running at about $9.8-10.3 \mathrm{~mL} / \mathrm{min}$ to give the desired total feed rate to the CSTRs of about $32 \mathrm{~mL} / \mathrm{min}$.

Because of the 32-mL/min flow rate to the CSTRs-which must be filled in the same manner that they are fed during operation (by introducing feed to CSTR1 and then overflowing to CSTR2 and the concentrate vessel)-the total time to fill the two CSTRs was about $16 \mathrm{~h}$ (an 8-h residence time in each CSTR). Another $3 \mathrm{~h}$ was required to add about $3 \mathrm{~L}$ of the diluted simulant liquid to the concentrate vessel from CSTR2 to fill the filter circulation loop before the actual start of filtration and to avoid forming foam from the air in all of the circulation loop tubing.

After filling CSTR1, which took about $9 \mathrm{~h}$ and $20 \mathrm{~min}$, the solution started to spill over into CSTR 2 and took about $8 \mathrm{~h}$ to fill and start to spill into the concentrate vessel. After about $3 \mathrm{~L}$ of feed had accumulated in the concentrate vessel, the waste feed pump and the water dilution pump were turned off to prepare for the actual NaTPB startup. The circulation pump was turned on, and the filter loop was filled. The nitrogen was turned on to the three vessels. The NaTPB, MST/dilution water, and the recycle wash water simulant were charged to their feed tanks, their feed pumps were turned on, and the flow was established to the CSTR. When all of the streams had reached the CSTR, the waste feed was restarted, officially beginning Test 1A on June 25, 1999. 


\subsubsection{Operation During Test 1A}

The various feed mixtures are added independently into the first CSTR through separate feed

lines. The TPB precipitates with sodium, potassium, and cesium in the high-salt supernatant waste simulant in the CSTR. The NaTPB is slightly soluble in the salt solution, and additional precipitation of potassium and cesium occurs over time. The slurry overflows into the second CSTR for an additional $8 \mathrm{~h}$ of reaction time. The slurry from the second CSTR overflows into the slurry concentration tank.

The slurry in the slurry concentration tank is recirculated through the cross-flow filter using a Moyno pump. Pressure-control valves adjust the transmembrane pressure in the filter unit in order to maintain a constant filtrate production rate that matches the feed rate to the first CSTR minus the slurry accumulation rate in the concentration step. Alternately, the pressure-control valve can be used to vary the filtrate production rate to maintain a constant level in the slurry concentration tank. In both cases, mass balance is maintained across the system. The filtrate is discharged to a filtrateproduct holding tank.

Operation of the filtration-loop pressure-control valves was controlled from the computer. The slurry-side back-pressure was controlled at $40 \mathrm{psi}$, and the Moyno pump speed was adjusted to obtain a flow rate of about $3.5 \mathrm{gal} / \mathrm{min}$. The speed was about $1460 \mathrm{rpm}$ during most of the test. The filtrate-control valve was adjusted to provide about $29-30 \mathrm{~mL} / \mathrm{min}$ of filtrate flow and, for most of the test, was controlled by the filtrate flow meter.

The valve was also controlled for a short time using the level meter in the slurry concentration vessel, but this practice had to be discontinued when the slurry got too thick and plugged the level-meter tube, which remained plugged for the rest of the test. The flow control worked well, and only slight problems occurred. No other operational problems were observed with the CSTRs or the filtration loop systems, and they all performed as designed, with the exception of the level meter.

The results of the analyses on the in-house strontium and cesium counting showed that CSTR1 and CSTR2 achieved the desired DF quickly. A DF of greater than 10,000 was attained by $20 \mathrm{~h}$ of operation. Measurements indicate that the DF reached a high value and gradually decreased to a steady-state value at about $60 \mathrm{~h}$. CSTR2 achieved a DF greater than 10,000 after $28 \mathrm{~h}$ of operation, an additional residence time. The DF leveled out after about $60 \mathrm{~h}$, as had CSTRl. The DF for the filtrate exceeded 10,000 after about $32 \mathrm{~h}$ and stayed relatively constant for the rest of the test. 
The strontium DF was also obtained at all three sample points. A DF of greater than 50 was obtained at both sample points 1 and 2 after about $20 \mathrm{~h}$ of operation. A filtrate DF for strontium greater than 50 was not obtained until 56-60 h. A uranium DF of about 2.5 was achieved in the filtrate.

After the 56-h samples had been analyzed, it was clear that both cesium and strontium DFs had been obtained, that the CSTR operation had almost achieved steady state, and that the filtrate DF was beginning to achieve steady state. It was then decided to shut the system down after $61 \mathrm{~h}$ of operation, or about 7.5 turnovers (residence times) in CSTR1. A couple of hours before shutdown, the control systems for both pressure control valves 1 and 2 were stepped up and down slightly to obtain process parameters under concentrated slurry conditions.

\title{
2. PROCESS CHEMISTRY AND THERMODYNAMICS
}

\author{
E. C. Beahm
}

\subsection{PREVENTION OF SOLIDS FORMATION (R. D. Hunt, E. C. Beahm, T. A. Dillow, and C. F. Weber)}

Contact: R. D. Hunt

Telephone: (423) 574-5481

Internet: huntrd@ornl.gov

Summary: The FY 1999 test plan includes the following:

1. an evaluation of the formation of aluminosilicates during caustic leaching;

2. viscosity measurements of actual process waste solutions as a function of temperature;

3. tests with selected components to link their concentrations, temperatures, and viscosities (initial experimental design based on a two-level seven-factor partial factorial); and

4. tests in support of other Tanks Focus Area (TFA) and user programs (primarily pipeline plugs).

Viscosity tests of several chemical components in the Hanford tank waste were performed at $80,70,60,50,45,40,35$, and $30^{\circ} \mathrm{C}$. With the exception of two samples, the viscosities of the samples remained below $4 \mathrm{cP}$, which is reasonable for waste transfers. However, the tests with the other two samples indicated that a plugged transfer pipe could occur between 30 and $35^{\circ} \mathrm{C}$. These two samples contained high concentrations of phosphate and silicon.

In a university contest, chemical and physical methods to remove pipeline plugs were evaluated. Several of the university groups tested modifications to the procedure in an effort to develop better plugs. While most of the modifications have been previously tested by TFA researchers, the input from the students will be used in the development of future plugs.

The SOLGAS program was used to predict the solubility of components in retrieval solutions and in the wash solutions and leachates from pretreatment processes. Two chemical systems, Na-F- 
$\mathrm{PO}_{4}-\mathrm{HPO}_{4}-\mathrm{OH}$ and $\mathrm{Al}-\mathrm{Na}-\mathrm{F}-\mathrm{PO}_{4}-\mathrm{HPO}_{4}-\mathrm{OH}-\mathrm{H}_{2} \mathrm{O}$, were evaluated. The results were used to develop operating envelopes that will avoid potential operational difficulties such as plugged pipelines. These operating windows were presented to Tank Waste Remediation System (TWRS) personnel.

\subsubsection{Purpose and Scope}

Nuclear waste remediation efforts at Hanford and Savannah River have been adversely affected by unwanted or unintentional solids formation. Transfer pipes at Hanford and Savannah River have become plugged with the nuclear waste, leading to schedule delays and to higher remediation costs. Fortunately, operating windows where solids can form during tank operations such as pretreatment, transfers, and storage can be predicted. These windows are based on thermodynamic calculations that use ionic strengths and the concentrations of phosphate, fluoride, silica, alumina, and hydroxide. To improve process control, it will also be necessary to correlate chemical effects and solid formation with physical properties that can be continuously monitored, if necessary. The properties of interest in many operations are viscosity and specific gravity. The ultimate aim is to provide relationships between the chemistry and physical properties so the tank farm operators can avoid unwanted or unintentional solids formation.

\subsubsection{Progress}

At the request of the TFA, a test plan for the FY 1999 research effort was submitted to the Pretreatment Technical Integration Manager. The approved test plan consists of the following research activities:

1. an evaluation of the formation of aluminosilicates during the caustic leaching of an actual sludge sample from a Hanford storage tank;

2. viscosity measurements of actual process waste solutions as a function of temperature;

3. tests with selected components to link their concentrations, temperatures, and viscosities (initial experimental design based on a two-level seven-factor partial factorial); and

4. tests in support of other TFA and user programs (primarily pipeline plugs).

\subsubsection{Viscosity Tests of Chemical Components in the Hanford Tank Waste (Task 3)}

The samples, which contain aluminum, fluoride, nitrate, hydroxide, phosphate, silicate, sodium, sulfate, and water, were shaken at $80^{\circ} \mathrm{C}$ for 2 weeks prior to the viscosity measurements. At the end of the $80^{\circ} \mathrm{C}$ tests, the samples were allowed to equilibrate at $70^{\circ} \mathrm{C}$ for 1 week prior to the next set of viscosity measurements. This procedure with a 1-week equilibration was repeated at 60 and $50^{\circ} \mathrm{C}$. All of the samples contained solids, which had settled to the bottom of the centrifuge tube. These solids were resuspended into the solution before most of the sample was transferred into the 
rheometer. The majority of the solids remained suspended during the viscosity tests. The viscosities of the samples at 60 and $50^{\circ} \mathrm{C}$ were less than $4 \mathrm{cP}$, which is reasonable for waste transfers. For the subsequent viscosity experiments, the equilibration time was reduced to 3.5 days. Viscosity measurements were taken at $45,40,35$, and $30^{\circ} \mathrm{C}$. With the exception of two samples, the viscosities of the samples remained below $4 \mathrm{cP}$. However, the tests with the other two samples indicated that a plugged transfer pipe could occur between 30 and $35^{\circ} \mathrm{C}$. These two samples contained high concentrations of phosphate and silicon. Additional tests will be performed at $25,20,15$, and $10^{\circ} \mathrm{C}$.

\subsubsection{University Contest on Methods to Unplug a Plugged Transfer Line (Task 4)}

Several groups of university students developed chemical and physical methods to remove pipeline plugs. Before these removal techniques were tested, the safety of the proposed procedures was evaluated by TFA personnel. The "safe" processes were then tested on a plugged section of pipe. The plug was prepared from chemicals that are found in the Hanford tank wastes. TFA researchers had developed the general procedure for the formation of the chemical plugs. Several of the university groups tested modifications to the procedure in an effort to develop better plugs. The modifications were evaluated during a conference call. While most of the modifications have been previously tested by TFA researchers, the input from the students will be used in the development of future plugs.

\subsubsection{Operating Envelopes (Task 4)}

An equilibrium solver routine was used to predict the solubility of components in retrieval solutions and in the wash solutions and leachates from pretreatment processes. Two chemical systems, Na-F-PO $-\mathrm{PO}_{4}-\mathrm{HPO}_{4}-\mathrm{OH}$ and $\mathrm{Al}-\mathrm{Na}-\mathrm{F}-\mathrm{PO}_{4}-\mathrm{HPO} \mathrm{O}_{4}-\mathrm{OH}-\mathrm{H}_{2} \mathrm{O}$, were evaluated with the SOLGAS program. Since these SOLGAS calculations rely on the standard free energy of formation, the minimum and maximum values for the free energy of formation for trisodium phosphate, sodium fluoride, sodium fluoride-phosphate double salt, and gibbsite were determined. The minimum and maximum values were then used to calculate the ranges of uncertainties in solubilities for the two chemical systems. For the Na-F- $\mathrm{PO}_{4}-\mathrm{HPO}-\mathrm{OH}$ system, the $\mathrm{NaOH}$ concentration was varied, while the total concentration of phosphate, fluoride, and aluminum was fixed in the $\mathrm{Al}-\mathrm{Na}-\mathrm{F}-\mathrm{PO}_{4}-\mathrm{HPO}_{4}$ $\mathrm{OH}-\mathrm{H}_{2} \mathrm{O}$ calculations. The results were used to develop operating envelopes that will avoid potential operational difficulties such as plugged pipelines. These windows were presented to TWRS personnel during the Saltcake Dissolution Workshop. 


\subsubsection{Publication}

P. Dai, H. A. Mook, S. M. Hayden, G. Aeppli, T. G. Perring, R. D. Hunt, and F. Dogan, "The Magnetic Excitation Spectrum and Thermodynamics of High- $T_{c}$ Superconductors," Science 284, 1344 (1999).

\section{MSRE REMEDIATION STUDIES}

\section{F. Williams}

\subsection{URANIUM CONVERSION (G. D. Del Cul, A. S. Icenhour, D. W. Simmons, and J. Caja)}

Contact: G. D. (Bill) Del Cul

Telephone: (423) 241-3596

Internet: gdf@ornl.gov

Summary: Fissile ${ }^{233} \mathrm{U}$ is presently being recovered, trapped, and removed as an essential part of the remediation and decommissioning activities presently under way at the Molten Salt Reactor Experiment (MSRE). Uranium hexafluoride trapped in $\mathrm{NaF}$, along with uranium-laden activated charcoal, represents the bulk of the inventory. For permanent storage, all of the uranium needs to be recovered and transformed into a stable oxide. Efforts focused on prototypical conversion of the $\mathrm{UF}_{6}$ sorbed on $\mathrm{NaF}$, preparation of uranium-laden passivated charcoal [auxiliary charcoal bed (ACB) simulant] for future conversion trials, preparation of the Building 4501 facility for conversion operations, and assembly and identification of the cold-test (mockup) apparatus. The conversion facility is scheduled to start the actual conversion operation in August 2000.

\subsubsection{Purpose and Scope}

The MSRE at Oak Ridge has been shut down since 1969, when the fuel salt was drained from the core into two drain tanks at the reactor site. In January 1994, analytical measurements of gas samples taken from the gas piping circuitry connected with the drain tanks indicated the presence of fluorine, $350 \mathrm{~mm} \mathrm{Hg}$, and uranium hexafluoride, $70 \mathrm{~mm} \mathrm{Hg}$. Although radiolysis was known to generate $\mathrm{F}_{2}$, the formation of $\mathrm{UF}_{6}$ and its transport from the fuel salt were unexpected. Additional investigation confirmed the belief that these gaseous products had moved through the piping to a charcoal bed. After these findings, a multiyear project was launched to remediate the potentially hazardous conditions generated by the movement of fissile material and reactive gases.

The extensive remediation and clean-up activities related to the MSRE involve (1) the trapping of the gaseous products; (2) deactivation, removal, and recovery of the uranium-laden activated charcoal; (3) stabilization and reconditioning of the fuel salt; and (4) conversion of ${ }^{233} U$ compounds into a stable oxide for final safe storage and disposition. One of the essential tasks is the recovery and conversion of all of the ${ }^{233} \mathrm{U}$ materials into a stable oxide for permanent storage. 


\subsubsection{Progress}

The $90 \%$ design of the conversion process was completed and is progressing toward as-built, $100 \%$ completion. Major components are being fabricated. Off-the-shelf procurement of instrumentation, piping, valves, and fittings is under way. The final process is being installed in the Building 4501 high bay, and it will be cold tested prior to installation in hot cell D. A mockup of the hot cell walls has been installed in the high bay, along with the in-cell table frame and crane. The manipulator mockup located in the Building 4501 high bay is being used to test special tools required for use in the hot cell and will also be used to cold test the entire system. The air-lock entrance to the facility was completed. Prototype testing of $\mathrm{NaF}$ system was completed ( $3 \mathrm{~kg}$ processed). Testing of the uranium-laden charcoal flow sheet was initiated. Future operations of the prototype will be performed to finalize procedures and for training purposes. The Safety Analysis Report and Technical Safety Requirements document for Building 4501 were submitted to DOE for review and approval. Plans and procedures (e.g., training, work control, operations, transportation) are being developed.

\subsection{RADIOLYSIS AND MATERIALS DISPOSITION STUDIES (D. F. Williams, A. S. Icenhour, L. D. Trowbridge, L. M. Toth, J. Brynestad, and B. B. Spencer) \\ Contact: D. F. Williams \\ Telephone: (423) 574-5769 \\ Internet:wni@ornl.gov}

Summary: Gas samples from the irradiation of uranium oxide and uranium oxyfluoride were analyzed. Results for the uranium oxide show no pressure increase. Gamma radiation removes oxygen from the uranium oxyfluoride matrix. Additional radiolysis experiments with these materials were initiated using the ${ }^{60} \mathrm{Co}$ source and a High Flux Isotope Reactor (HFIR) spent nuclear fuel element. The final irradiated MSRE fuel salt simulant was removed from HFIR, and preparations were made to conduct a large-scale pool-melt demonstration (progressive melting using a central heating probe). The final report (ORNL/TM-13770) on evaluation of non-gas-generating fluorinetrapping agents for use during storage of the MSRE fuel salt was issued.

\subsubsection{Purpose and Scope}

Understanding the radiolysis of MSRE fuel salt, uranium oxides, and other materials that derive from conversion of the recovered $\mathrm{UF}_{6}$ is necessary in order to proceed with remediation, interim storage, and permitted storage of the radioactive MSRE materials. The most significant remediation activities for the MSRE include (1) removal and recovery of uranium from the off-gas system, (2) removal of the uranium-laden charcoal from the charcoal bed, and (3) removal of the stored fuel sait. These retrievable intermediate materials are not suitable for long-term storage and 
must be converted to a more stable form. In the case of the MSRE fuel salt, it is also necessary to understand the chemical consequences of the radiolysis in order to safely melt and treat the salt. A recent addition to the scope of this work has included short-term tests and analyses to support the interim storage of materials before they are converted into stable oxides.

\subsubsection{Progress}

Radiolysis studies were conducted in support of the development of the ${ }^{233} \mathrm{U}$ storage standard. Samples that had been placed in the ORNL ${ }^{60} \mathrm{Co}$ irradiator during the previous quarter were removed, and gas samples were withdrawn. The irradiated uranium oxide samples (i.e., $\mathrm{UO}_{3} \cdot x \mathrm{H}_{2} \mathrm{O}$ and $\mathrm{U}_{3} \mathrm{O}_{8}$ ), which were loaded in air, showed an overall decrease in pressure $(\sim 20$ to 30 torr $)$ and the depletion of oxygen in the gas. Analysis of gas samples from the $\mathrm{UO}_{2} \mathrm{~F}_{2}$ containers revealed the production of oxygen. Davies-Gray titration of these $\mathrm{UO}_{2} \mathrm{~F}_{2}$ samples and those from earlier experiments showed an increase in the amount of U(IV) upon gamma irradiation. This result, combined with observed color change in the $\mathrm{UO}_{2} \mathrm{~F}_{2}$ (from yellow to green) and the production of oxygen, leads to the conclusion that oxygen is liberated from the $\mathrm{UO}_{2} \mathrm{~F}_{2}$ matrix upon irradiation. In the event that carbon impurities are present, $\mathrm{CO}_{2}$ would be produced, as has been observed. A sample of $\mathrm{UO}_{2} \mathrm{~F}_{2}$ was burned in $\mathrm{O}_{2}$ to remove carbon impurities and then placed in the ${ }^{60} \mathrm{Co}$ irradiator. Gas samples from this experiment will be withdrawn during the next quarter. Additionally, gamma irradiation of $\mathrm{UO}_{2} \mathrm{~F}_{2}$ using a HFIR spent fuel element was initiated. This high-dose-rate experiment should give information on the maximum damage limit for the $\mathrm{UO}_{2} \mathrm{~F}_{2}$.

The final 800-g sample of MSRE fuel salt simulant was removed from the HFIR spent fuel cooling pool after it had developed a fluoride deficiency of $0.24 \mathrm{meq} / \mathrm{g}$-salt. Most of the saltdevelopment activities focused on testing the prototype pool-melting probe and preparing the Building 4501 high bay for this activity. Preliminary small-scale tests with chloride salts give us confidence that this prototype heater will work well with the actual MSRE coolant salt to be used during the development/demonstration. Demonstration of restoration of fluorine to the radiolyzed salt by hydrofluorination is scheduled to occur after the pool-melt demonstration.

\subsection{INVITED CONFERENCES}

A. S. Icenhour, "Radiolysis Studies for the ${ }^{233} U$ Storage Standard," presented to the DNFSB 97-1 Technical Tcam Mecting \#17, Albuquerque, New Mexico, June 23-24, 1999.

D. F. Williams, G. D. Del Cul, and L. M. Toth, "Molten Salt Fuel Cycle Requirements for ADTT Applications," presented at the 3rd International Conference on Accelerator Driven 
Transmutation Technologies and Applications (ADDTA 99), Prague, Czech Republic, June $7-11,1999$.

\subsection{PUBLICATION}

D. F. Williams and J. Brynestad, Evaluation of Fluorine-Trapping Agents for Use During Storage of the MSRE Fuel Salt, ORNL/TM-13770, Oak Ridge, Tennessee, May 1999.

\section{CHEMISTRY RESEARCH}

\section{F. Williams}

\subsection{MOLECULAR IMPRINTING ON SOL-GEL MATRICES (S. Dai, Y. H. Ju, M. C.} Burleigh, and S. D. Waezsada)

Contact: S. Dai

Telephone: (423) 576-7307

Internet: dais@ornl.gov

Summary: Hybrid materials using an ordered mesoporous substrate with anion-exchange functionality were prepared by hydrolysis using the micellar template approach. The prepared samples were characterized via infrared spectroscopy, nitrogen sorption, and small-angle X-ray scattering (SAXS). The uptakes of anionic thorium nitrate complexes by the new resins in $8 \mathrm{~N}$ nitric acid solutions were determined. The thorium-loading capacity of the hybrid mesoporous silica functionalized with $\mathrm{N}$-trimethoxysilylpropyl-N, N, N-tri-n-butylammonium chloride (TSPBC) is greater than that of the hybrid mesoporous silica functionalized with $\mathrm{N}$-trimethoxylsilylpropyl-N, $\mathrm{N}$, $\mathrm{N}$-trimethylammonium chloride (TSPMC). These hybrid anion-exchange resins were shown to be much more selective than a popular commercial organic anion-exchange resin.

\subsubsection{Purpose and Scope}

The purpose of this research is to incorporate molecular recognition in advanced sorbent development. The design principles illustrated by these results highlight opportunities for application of imprint-coated mesoporous materials in areas such as selective sorption, chemical sensing, and catalysis.

\subsubsection{Progress}

The synthetic procedure to produce ordered mesoporous hybrid sorbents is similar to that of coassembling synthesis. The typical procedure for preparation of mesoporous silica functionalized with quaternary ammonium ion involves mixing cetyltrimethylammonium bromide (CTAB), tetramethylorthosilicate (TMOS), TSPBC, water, and base $(\mathrm{NaOH})$. The respective molar ratios of CTAB, TMOS, TSPBC, $\mathrm{H}_{2} \mathrm{O}$, and $\mathrm{NaOH}$ are $0.12,1,0.15,130$, and 0.7 . The mixture is then heated at $100^{\circ} \mathrm{C}$ for $24 \mathrm{~h}$. The white solid product is recovered by filtration. The residue is then refluxed 
in ethanol/ $\mathrm{HCl}(100: 1)$ for $24 \mathrm{~h}$ and washed with copious amounts of $1 \mathrm{NHNO}_{3}$ to remove surfactant templates. The resulting gel is placed under vacuum at $80^{\circ} \mathrm{C}$ for $4 \mathrm{~h}$. The mesoporous anion-exchange resins functionalized with TSPMC and 1-trimethoxysilylpropyl-3-guanidine chloride (TSPGC) were prepared using a similar protocol.

SAXS analysis of the surfactant-free hybrid mesoporous sorbents shows a peak around $\mathrm{q}=2 \mathrm{~nm}^{-1}$, which agrees with the corresponding pore size determined by nitrogen-adsorption experiments. This indicates that the long-range order induced by the surfactant templates is retained for the surfactant-extracted anion-exchange resins. The infrared spectrum of the resin functionalized with TSPGC has some extra bands around $3400-3000 \mathrm{~cm}^{-1}$, which can be attributed to the stretches associated with $=\mathrm{N}+\mathrm{H}_{2}$. The $\mathrm{N}_{2}$ adsorption isotherms of the mesoporous anion-exchange resins all have a step around $0.1-0.4 \mathrm{p} / \mathrm{p}_{0}$, which is characteristic of mesoporous materials. The large surface area of our mesoporous hybrid $\left(>100 \mathrm{~m}^{2} / \mathrm{g}\right)$ is due to the effect of the surfactant template during synthesis. The surface areas of the same hybrid resins prepared without the use of the surfactant template are much smaller and in the range of $1-10 \mathrm{~m}^{2} / \mathrm{g}$. This demonstrates the importance of using surfactant templates in synthesizing hybrid sol-gel sorbents. The adsorption test will be conducted in the next quarter.

\subsection{IONIC LIQUIDS RESEARCH (S. Dai and Y. H. Ju)}

Contact: S. Dai

Telephone: (423) 576-7307

Internet: dais@ornl.gov

Summary: The synergistic anion effect on solvent extraction based on ionic liquids was investigated. Four anionic systems were employed in this investigation. No synergistic effect has been found.

\subsubsection{Purpose and Scope}

The purpose of this research is to conduct a spectroscopic investigation into the fundamental interaction between ionic solvents and solutes in both low-temperature and high-temperature ionic liquids (e.g., molten salts). The fundamental knowledge gained in these studies will be used to design novel separation systems involving ionic liquids.

\subsubsection{Progress}

The extraction distribution coefficients for four anionic systems with the same cationic species, $\left.\mathrm{Sr}^{2+}\left[\mathrm{Sr}\left(\mathrm{NO}_{3}\right)_{2}, \mathrm{SrCl}_{2}, \mathrm{SrI}_{2}, \mathrm{SrBr}_{2}\right)\right]$, were obtained by the batch method using inductively 
coupled plasma-atomic emission (ICP-AE) detection after a 24-h equilibration time. The ionic liquid used in this investigation was 1-ethyl-3-methylimidazolium bis(trifluoromethylsulfonyl)amide. The distribution coefficients for all four anionic systems were very similar (same order of magnitude). This behavior is different from that of ion-pair solvent extraction systems, which are highly dependent on the identity of the counteranions.

\subsection{INVITED CONFERENCE}

S. Dai, "Molecular Recognition in Sol-Gel Glasses and Ionic Media," presented at the DOE Separation Workshop, Savannah, Georgia, April 1999.

\subsection{PUBLICATIONS}

S. D. Wallace, J. M. Hiller, and S. Dai, Neutron Detection Based Upon a Lithiated Sol-Gel Glass, Y/DW-1766, Oak Ridge, Tennessee, May 1999.

Y. S. Shin, M. C. Burleigh, S. Dai, C. E. Barnes, and Z. L. Xue, "Investigation of Uranyl Adsorption on Mesoporous Titanium-Based Sorbents," Radiochim. Acta 84, 37 (1999).

S. Dai, M. C. Burleigh, Y. S. Shin, C. C. Morrow, C. E. Barnes, and Z. L. Xue, "Imprint Coating: Novel Synthesis of Selective Functionalized Ordered Mesoporous Sorbents," Angew. Chem. Int. Ed. 38, 1235 (1999).

\section{SEPARATIONS AND MATERIALS SYNTHESIS}

D. W. DePaoli

5.1 CHEMICAL AND PHYSICAL PRINCIPLES IN MULTIPHASE SEPARATIONS (D. W. DePaoli, V. F. de Almeida, C. Tsouris, D. D. Bruns, B. A. Grant, and S. U. Sarnobat)

Contact: D. W. DePaoli

Telephone: (423) 574-6817

Internet: ddi@ornl.gov

Summary: Fundamental studies of multiphase systems, particularly those that explore the use of electromagnetic fields to enhance transport processes, are continuing. Progress has been made in several areas, including (1) spraying and mixing in electrohydrodynamic (EHD) flows, (2) investigation of multiphase flows through experimental studies and high-performance computing simulations, and (3) particle interactions under magnetic fields and in reactive systems. 


\subsubsection{Purpose and Scope}

This program, funded by the DOE Office of Basic Energy Sciences, comprises several fundamental studies that explore transport processes in multiphase separations, with particular emphasis placed on the application of electromagnetic fields for enhancement. Experimental, theoretical, and computational methods are employed to investigate the effect of electromagnetic fields on transport processes in liquid-liquid, gas-liquid, and solid-liquid systems. This work will provide information necessary to devise novel means to dramatically improve transport rates in these systems and, thus, will have widespread benefit for separations processes such as solvent extraction and distillation as well as applications in environmental and biotechnology areas. The areas of current focus are (1) enhancement of transport processes through EHD flows and (2) interactions and coalescence/aggregation of particles and drops.

\subsubsection{Progress}

This project was represented at the Third DOE/Basic Energy Sciences Separations Research Workshop in a presentation titled "Enhancement of Transport Processes in Multiphase Systems." In addition to highlighting recent results on EHD spraying and mixing and their application to ultrafine particle production, the presentation discussed scientific challenges involved in understanding multiphase processes and modern approaches to these challenges. It outlined recent developments in computing capabilities of teraflop distributed parallel computers, modern algorithms, and emerging simple models of complex physics as promising means of advancing the understanding and application of multiphase flows.

\subsubsection{Electrohydrodynamic Spraying and Mixing}

A dimensional-analysis approach was employed to determine which parameters are responsible for pumping, spraying, and mixing phenomena caused by EHD flows. Based on experimental data using a phase-Doppler velocimeter, a relationship of the flow velocity with physical properties, geometry, and operating conditions was derived. A paper titled "Effects of Electric Fields on Bubble and Particle Velocities in Water and Alcohols" was submitted for publication.

\subsubsection{Nonlinear Bubble Production}

Experimental studies of the dynamics of bubble formation by inverse electrostatic spraying have continued. An automated data acquisition system was developed and employed to explore the entire flow regime from periodic to chaotic bubbling for injection of nitrogen into glycerin, both with and without an applied electric field. The results show that voltage can be an additional control 
parameter, adding new dimensions to the bifurcation perspective; using voltage to drive the system into chaos could lead to applications for increased mass and heat transfer in fluidized beds, distillation columns, etc.

\subsubsection{Gas-Liquid Hydrodynamics}

A prototype system has been identified for the study of basic aspects of gas-liquid hydrodynamics in distillation towers. A parallel-corrugated-plate apparatus (PCPA) was designed for visualization of gas-liquid countercurrent flow through cross-corrugated parallel plates. The apparatus will be used to investigate basic aspects of flow, dispersion, and mass transfer in distillation towers constructed with structured packings. The emerging lattice-Boltzmann method has been identified as an appropriate technique to model two-phase flow in the PCPA. A DEC Alpha workstation has been configured for initial computer-aided modeling development.

\subsubsection{Particle Interactions Under Magnetic Fields}

Studies of the aggregation of colloidal magnetic particles and formation of chains continued, with a focus on secondary-minimum aggregation and breakup of aggregates. A quantitative agreement between experiments and simulations was obtained for the transition from secondary- to primary-minimum aggregation.

\subsection{NUCLEATION, GROWTH, AND TRANSPORT PHENOMENA (M. Z.-C. Hu, C. H. Byers, K. R. Booth, B. A. Grant, M. Shah, and J. Thomas)}

Contact: M. Z.-C. Hu

Telephone: (423) 574-8782

Internet: i5h@ornl.gov

Summary: This project aims to develop understanding of nucleation and growth of clusters/particles involved in homogeneous or heterogeneous systems. Dielectric tuning solution (DTS) coprecipitation was proven to be a successful route for the synthesis of monodispersed zirconium titanate $\left(\mathrm{ZrTiO}_{3}\right)$ microsphere particles.

\subsubsection{Purpose and Scope}

This research program, funded by the Office of Basic Energy Sciences, involves materials chemistry and synthesis and fundamental studies of nucleation and growth phenomena in chemically reactive systems for synthesis of ultrafine (particularly nanosized), monodispersed particles (i.e., oxide ceramic precursor powders) and for solution deposition of ceramic films. A primary goal is the understanding of the mechanisms, kinetics, and thermodynamics of nucleation and particle growth under controlled sol-gel and wet-chemical processing conditions. 
Our current emphasis in nanoscale/nanostructured materials lies with the chemistry, reaction engineering, colloidal/interfacial science, and materials science involved with three major wetchemical systems: (1) homogeneous precipitation of nanospheres and microspheres in inorganic salt solutions of mixed solvent, (2) hydrothermal processing of inorganic salt aqueous solutions, (3) acidor base-catalyzed hydrolysis and condensation of organometallic compounds (such as alkoxides) in water-alcohol solutions, and (4) ceramic film deposition onto self-assembled monolayers in solutions. Experiments utilize several specially developed techniques, including real-time dynamic light scattering (DLS) and rapid-mixing flow cell coupled with Fourier transform infrared (FTIR) and SAXS, as well as high-temperature X-ray diffraction (XRD), electron microscopy, Raman spectroscopy, and electrostatic spraying.

It is anticipated that the results of this work will have significant impacts upon development of advanced materials such as nanoscale and nanophase ceramics that have dramatically improved properties over traditional "coarse-grained" ceramics. These advanced ceramics are potential candidates as structural ceramics, electroceramics, catalysts, nanocrystalline thin films, coatings, and nanostructured inorganic membranes.

\subsubsection{Progress}

The DTS synthesis methodology was extended to the binary systems including barium titanate $\left(\mathrm{BaTiO}_{3}\right)$ and zirconium titanate $\left(\mathrm{ZrTiO}_{3}\right)$. Direct DTS coprecipitation failed for the barium titanate; however, it achieved success in the production of monodispersed zirconium titanate particles. Zirconium titanates are among the most widely used microwave dielectrics for filters or resonators. High-resolution transmission electron microscopy and XRD studies showed that the as-prepared $\mathrm{ZrTiO}_{3}$ microspheres are amorphous materials achieving molecular-level homogeneity in composition. In situ high-temperature XRD and thermogravimetric analysis/differential thermal analysis (TGA/DTA) data show that the amorphous materials start to crystallize around $650^{\circ} \mathrm{C}$ and that the particle synthesis condition is not affected significantly at this crystallization temperature. A microwave processing technique was also attempted to rapidly heat the solutions, which produced nanosized, monodispersed particles of zirconium titanate in a few seconds. 


\subsection{PHASE EQUILIBRIA MODIFICATION BY ELECTRIC FIELDS (C. Tsouris, K. D. Blankenship, D. W. DePaoli, M. Dinsmore, J. Dong, N. B. Handagama, S. Z. Yiacoumi, and T.-Y. Ying)}

Contact: C. Tsouris

Telephone: (423) 241-3246

Internet: tq9@ornl.gov

Summary: Fundamental studies are being undertaken that explore the use of electric fields to modify phase equilibria in multiphase separations processes. Experimental systems have been assembled and are currently used to investigate transport and thermodynamic effects of electric fields on vapor-liquid and liquid-liquid systems. Batch-distillation, vapor-liquid-equilibria, liquid-liquidequilibria, and solid-liquid-equilibria experiments are in progress, using various liquid mixtures of polar-nonpolar, polar-polar, and nonpolar-nonpolar components. The results obtained to date show that electric fields have an effect on the vapor-liquid and solid-liquid equilibria of some systems.

\subsubsection{Purpose and Scope}

The primary objective of this project, funded by the Environmental Management Science Program, is to enhance separations of mixtures by applying an electric field across an interface between two phases. Enhancement in separation may be achieved either by increasing transport rates through the interface or by changing the phase equilibria. Electric fields have been known to interact with charge carriers, such as ions and electrons, leading to higher mass-and heat-transfer rates, fluid atomization, mixing, and pumping, which are transport effects. The effects of electric fields on the behavior of noncharged molecules and ions and the macroscopic thermodynamic behavior of the system are examined in this project.

\subsubsection{Progress}

Experiments were conducted in which a stirred tank was used to form a liquid-liquid dispersion and an electric field then applied to manipulate the properties of the dispersed and continuous phases. The effect of an electric field on the ambivalence region (i.e., the region in which either phase may be continuous or dispersed) was investigated. It was found that the ambivalence region is strongly modified by the electric field to the point that, by turning the field on and off, one may invert the phases back and forth. In addition, the drop size of the dispersed phase can be manipulated by applying a lower voltage than that needed for phase inversion. An invention disclosure on this topic was elected by Lockheed Martin Energy Research Corporation.

Solid-liquid-equilibria, or electrosorption, experiments were also continued to investigate the effect of electric fields on the separation of ions from aqueous solutions. Experiments are conducted 
to investigate both equilibrium and kinetic effects of electric fields. Modeling studies were continued in collaboration with investigators at Georgia Institute of Technology.

\subsection{ELECTROSTATIC OZONATION (C. Tsouris, D. W. DePaoli, S. Yiacoumi, and W.-T. Shin)}

Contact: C. Tsouris

Telephone: (423) 241-3246

Internet: tq9@ornl.gov

Summary: Electric fields are used to form microbubbles containing ozone for the oxidation of organic pollutants in aqueous solutions. An experimental apparatus has been set up for (1) ozone generation from air or oxygen by means of corona discharge; (2) ozone spraying in an aqueous phase containing an organic solute, such as phenol, by inverse electrostatic spraying; and (3) collection of gas and liquid samples for chemical analysis. Experimental results showed an enhancement in the oxidation rate by electrostatically generated microbubbles, as compared with conventional bubble diffusers.

\subsubsection{Purpose and Scope}

The primary objective of this project, funded by the Electric Power Research Institute, is to enhance the efficiency of ozonation processes by inverse electrostatic spraying. Ozone is a strong oxidant of organic molecules with fast reaction kinetics; thus, in most cases, ozonation is a masstransfer-limited process that can be improved by decreasing the size of ozone-containing gas bubbles. Introduction of ozone in the form of microbubbles enhances the oxidation efficiency by (1) increasing the surface area per unit volume between the gas and liquid phases and (2) increasing the gas volume fraction (since smaller bubbles have a lower rise velocity than larger bubbles). This project is aimed at applying the knowledge gained in our fundamental studies of inverse electrostatic spraying to develop an efficient means for production of ozone-containing microbubbles.

\subsubsection{Progress}

Experiments including (1) mass transfer of ozone from the bubbles to deionized water, (2) oxidation of methylene blue dissolved into water, and (3) oxidation of phenol were continued. Results showed that radicals are formed in solution during electrostatic spraying of oxygen under electrical-discharge conditions; it was also found that phenol and methylene blue are oxidized at accelerated rates. Modeling studies of phenol oxidation under electrical discharge have continued. 


\subsection{OZONE TREATMENT OF SOLUBLE ORGANICS IN PRODUCED WATER (D. W. DePaoli, K. T. Klasson, C. Tsouris, and A. B. Walker)}

Contact: D. W. DePaoli

Telephone: (423) 574-6817

Internet: ddi@ornl.gov

Summary: Studies have continued on the destruction of water-soluble organics from aqueous solutions similar to produced water. The results obtained to date have shown that it is possible to achieve nearly complete destruction with ozone alone if mass-transfer limitations are overcome through the introduction of gas in the form of microbubbles. Testing will continue with a bench-scale continuous process.

\subsubsection{Purpose and Scope}

Oil production is shifting from "shallow" wells (0- to 650 -ft water depth) to offshore deepwater operations ( $>2600 \mathrm{ft}$ ). Production from these operations is now less than $20 \%$. By 2007 , it is projected that as much as $70 \%$ of the U.S. oil production will be from deepwater operations. The crude oil from these deep wells is more polar, increasing the amount of dissolved hydrocarbons in the produced water. Existing physical/chemical treatment technologies used to remove dispersed oil from produced water will not remove dissolved organics.

This project, funded by the Office of Fossil Energy, is aimed at devising compact, low-cost, efficient treatment processes to comply with current and future water quality regulations. It is an extension of previous research to improve the applicability of ozonation for treating organics and will help address the petroleum industry-wide problem of handling soluble organics from deepwater operations. The goal of this project is to maximize oxidation of water-soluble organics during a single-pass operation. The project investigates (1) producing oxidants by electrochemical and sonochemical methods, (2) increasing the mass-transfer rate by forming microbubbles during ozone injection into the produced water, and (3) using ultraviolet irradiation to enhance the reaction if needed.

\subsubsection{Progress}

A milestone report on bench-scale studies was delivered in May. This report highlighted results obtained by both sonochemical and ozonation methods for destruction of dissolved (1) benzene, toluene, ethylbenzene, and xylene; (2) hexanoic acid; and (3) crude oil. Based on those results, work is now focused on ozonation using microbubbles. A novel electrochemical ozone generator obtained from a collaborating vendor was set up to test enhancement of oxidation at 
elevated ozone concentrations; however, we have not yet been able to produce ozone at concentrations significantly higher than that produced by a conventional ozone generator.

\subsection{ELECTRICALLY DRIVEN TECHNOLOGIES FOR RADIOACTIVE AEROSOL ABATEMENT (D. W. DePaoli, V. F. de Almeida, C. Tsouris, C. Riahi-Nezhad, and C. H. Mattus) \\ Contact: D. W. DePaoli \\ Telephone: (423) 574-6817 \\ Internet: ddi@ornl.gov}

Summary: Studies have been initiated in collaboration with The University of Texas to study the effects of electric and acoustic fields on the interactions of aerosol particles. Coupled experimental and computational methods are under development.

\subsubsection{Purpose and Scope}

The objective of this research program, funded by the Environmental Management Science Program and conducted in collaboration with $O$. A. Ezekoye of The University of Texas at Austin, is to develop an improved understanding of how electrically driven processes (including electrocoalescence, acoustic agglomeration, and electric filtration) may be employed to efficiently treat problems caused by the formation of aerosols during DOE waste treatment operations. The production of aerosols during treatment and retrieval operations in radioactive waste tanks presents significant problems of cost, worker exposure, potential for release, and increased waste volume. Electrically driven technologies offer promise as remote methods for improved treatment; however, existing theoretical models are not suitable for performance prediction and design.

In most particulate collection technology, the marginal collection efficiency increases as the aerosol to be separated increases in size. We are investigating mechanisms for increasing the size of particles in an effluent stream as a preprocessing step. Our work is aimed at employing recent advances in theoretical approaches and experimental techniques to improve our understanding of how electrical and acoustic methods may be employed most efficiently-alone or in tandem-to tackle aerosol problems. The fundamental understanding achieved may provide the basis for development of innovative new approaches and for optimizing removal processes.

\subsubsection{Progress}

On June 2 and 3, 1999, meetings were conducted with the research group of O. A. Ezekoye. at The University of Texas. In these meetings, details of coupled experimental and theoretical approaches to study the interactions of particles in acoustic and electric fields were determined. A 
pair of instrumented chambers will be constructed, one at each research facility, to observe the particle size distribution and density under various combinations of flow and applied acoustic and electric fields.

A prototype computational system has been identified for study of particle interactions embedded in a viscous fluid in the presence of acoustic and electric fields. The method of analysis employs particle dynamics via the lattice-Boltzmann method.

\subsection{IMPROVED DECONTAMINATION: INTERFACIAL, TRANSPORT, AND CHEMICAL PROPERTIES OF AQUEOUS SURFACTANT CLEANERS (D. W. DePaoli, R. M. Counce, M. Z.-C. Hu, and A. W. Rowe)}

Contact: D. W. DePaoli

Telephone: (423) 574-6817

Internet: ddi@ornl.gov

Summary: Laboratory-scale experimentation is under way to determine improved means for decontamination using aqueous surfactant cleaners. Studies have shown that the removal of oil from metal surfaces is highly dependent on process conditions. In addition, we have found that through a simple modification of process conditions, we can greatly improve the speed of oil removal.

\subsubsection{Purpose and Scope}

This investigation, funded by the Environmental Management Science Program, is focused on decontamination using environmentally benign aqueous solutions, specifically the removal of organics and associated radionuclide and heavy metal contaminants by surfactants. Aqueous-based solutions promise several advantages for decontamination processes, including low hazard potential, low cost, and reduced secondary waste volume through solvent recycle, solvent degradation, and/or incineration.

The work is intended to provide an understanding of interfacial, transport, and chemical processes that govern the effectiveness of aqueous-based surfactant solutions for decontamination of surfaces. In addition, efficient means for separation of waste materials from aqueous-based cleaners will be investigated. It is intended that the understanding developed in this work will be applied to decontamination/decommissioning tasks by laboratory testing of samples from contaminated DOE sites and that the tests will provide the basis for improved approaches to the removal of organic contamination. 


\subsubsection{Progress}

Experiments have continued to study the effect of process conditions on the removal of oil films from metal coupons in a commercial sonicator bath. While the results show consistent trends with single-droplet experiments, drastically different results are obtained depending on the nature of the surfactant (e.g., anionic, nonionic, and cationic). To further probe this issue, experiments will continue with a zwitterionic surfactant at different $\mathrm{pH}$ levels.

\subsection{PUBLICATIONS}

K. D. Blankenship, D. W. DePaoli, J. O. Hylton, and C. Tsouris, "Effect of Electrode Configurations on Phase Equilibria with Electric Fields," Sep. Purif. Technol. 15, 283-94 (1999).

K. D. Blankenship, V. M. Shah, and C. Tsouris, "Distillation Under Electric Fields," Sep. Sci. Technol. 34, 1393-1409 (1999).

S. Relle, S. B. Grant, and C. Tsouris, "Diffusional Coagulation of Superparamagnetic Particles in the Presence of an External Magnetic Field," accepted for publication in Physica A (1999).

W.-T. Shin, A. Mirmiran, S. Yiacoumi, and C. Tsouris, "Ozonation Using Microbubbles Formed by Electric Fields,” Sep. Purif. Technol. 15, 271-82 (1999).

A. Singhal, G. Beaucage, M. T. Harris, L. M. Toth, K. D. Keefer, J. S. Lin, M. Z.-C. Hu, and J. R. Peterson, "Structure and Growth Kinetics of Zirconium Hydrous Polymers in Organic Solutions," J. Non-Cryst. Solids 246, 197-208 (1999).

K. Subramaniam, S. Yiacoumi, and C. Tsouris, "Effect of Copper and Cadmium Binding on Flocculation of Ferric Oxide Particles," Sep. Sci. Technol. 34, 1301-18 (1999).

C. Tsouris, W.-T. Shin, S. Yiacoumi, and D. W. DePaoli, "Effects of Electric Fields on Bubble and Particle Velocities in Water and Alcohols," submitted for publication in Journal of Colloid and Interface Science (May 1999).

C. Tsouris, A. P. Borole, E. N. Kaufman, and D. W. DePaoli, “An Electrically Driven Gas-LiquidLiquid Contactor for Bioreactor and Other Applications," Ind. Eng. Chem. Res. 38, 1877-83 (1999).

T.-Y. Ying, C. J. Chin, S.-C. Lu, S. Yiacoumi, M. R. Chattin, M. A. Spurrier, D. W. DePaoli, and C. Tsouris, "Magnetic-Seeding Filtration," Sep. Sci. Technol. 34, 1371-92 (1999).

\subsection{PRESENTATIONS}

C. J. Chin, S. Yiacoumi, and C. Tsouris, "Aggregation of Superparamagnetic Particles and Breakup of Magnetic Aggregates," presented at the 73rd American Chemical Society Colloid and Surface Science Symposium, Massachusetts Institute of Technology, Cambridge, Massachusetts, June 13-16, 1999. 
D. W. DePaoli, V. F. de Almeida, and C. Tsouris, "Enhancement of Transport Processes in Multiphase Systems," presented at the Third DOE/Basic Energy Sciences Separations Research Workshop, Savannah, Georgia, May 12-14, 1999.

M. Z.C. Hu, "Monodispersed Barium Titanate Microspheres from Inorganic Precursors," presented at the 101st Annnual Meeting and Expositions, American Ceramic Society, Indianapolis, Indiana, April 25-28, 1999.

C. Tsouris, D. W. DePaoli, and S. Yiacoumi, "Novel Environmental Technologies Driven by Electric and Magnetic Fields," presented at the Environmental Technologies and Opportunities Forum, Oak Ridge, Tennessee, June 1, 1999.

C. Tsouris and J. Dong, "Electric-Field Effects on Fluid Interfaces," presented at the 73rd American Chemical Society Colloid and Surface Science Symposium, Massachusetts Institute of Technology, Cambridge, Massachusetts, June 13-16, 1999.

\section{FLUID STRUCTURE AND PROPERTIES}

\section{H. D. Cochran}

\subsection{INTERACTIONS OF SOLUTES, SOLVENTS, AND SURFACES (H. D. Cochran, H. J. Dai, H.-C. Li, and K. D. Heath)}

Contact: H. D. Cochran

Telephone: (423) 574-6821

Internet: hdc@ornl.gov

Summary: Molecular-based studies performed on systems with supercritical solvents include X-ray and neutron-scattering experiments, molecular simulations, and integral equation theory to pursue fundamental understanding of how they behave in practical separations processes.

\subsubsection{Objective}

This program focuses on our fundamental interest in understanding the practical behavior of separation processes in terms of the underlying molecular interactions. Currently, the work focuses on systems with supercritical solvents and systems with surfactants that form micelles.

\subsubsection{Progress}

K. D. Heath has completed his Ph.D. dissertation on electrodispersion of aqueous media into supercritical $\mathrm{CO}_{2}$. Mean droplet size was found to correlate with interfacial tension as a function of temperature and pressure. In mass-transfer experiments, entrainment of the micron-size droplets was found to be negligible, implying that coalescence on the wire-mesh electrode was very efficient, probably as a result of the droplets being charged. 
Efforts by H.-C. Li and H. J. Dai yielded suggestive evidence for the existence of micelles in molten salt systems at near-ambient temperatures. Repetition of the neutron-scattering experiments with deuterated $n$-decane solute indicated that structures of $\sim 200-\mathrm{nm}$ diam were present; reexamination revealed earlier X-ray scattering results were consistent with this interpretation.

Li has initiated efforts to develop intermolecular potential models for perfluoropolycthers that constitute the $\mathrm{CO}_{2}$-philic tails of some successful surfactants. Ab initio calculations using Gaussian 98 have been performed to determine electron density in five small perfluoroether compounds.

Our paper "Supercritical Carbon Dioxide Extraction of Lipids from Pythium irregulare" has been published in the Journal of the American Oil Chemists' Society. Our paper "Small Angle Neutron Scattering from Polymers in Supercritical Carbon Dioxide" has been published in Neutron News. Our papers "Pressure and Temperature-Induced Transitions in Polymer Solutions in Supercritical Fluids" and "SANS Studies of Polymers in Organic Solvents and Supercritical Fluids in Poor, Theta, and Good Solvent Domains" have been accepted by Macromolecules and the ACS Symposium Series, respectively.

\subsection{MOLECULAR-BASED STUDY OF REVERSE MICELLES IN SUPERCRITICAL $\mathrm{CO}_{2}$ (P. T. Cummings, H. D. Cochran, G. D. Wignall, J. M. DeSimone, E. J. Beckman, Yu. B. Melnichenko, S. T. Cui, S. Salaniwal, and K. D. Heath)}

Contact: H. D. Cochran

Telephone: (423)574-6821

Internet: hdc@ornl.gov

Summary: This multi-institutional project aims to develop a molecular understanding of reverse micelles in supercritical carbon dioxide through small-angle scattering experiments and molecular simulation calculations and, in particular, to determine what molecular characteristics lead to successful surfactants for this application.

\subsubsection{Objective}

The aim of this multi-institutional project is to develop a molecular understanding of reverse micelles in supercritical carbon dioxide through small-angle scattering experiments and molecular simulation calculations and, in particular, to determine what molecular characteristics lead to successful surfactants for this application. 


\subsubsection{Progress}

Molecular dynamics simulations of reverse micelles with aqueous cores in supercritical carbon dioxide have continued. We have found that aggregation into reverse micelles proceeds according to the kinetic theory of Smoluchowski for diffusion-limited coalescence. We have found that coalescence rarely occurs if contact exists only between surfactant tails but almost always occurs when there is contact between aqueous cores.

Our paper "Vapor-Liquid Phase Coexistence of Alkane- $\mathrm{CO}_{2}$ and Perfluoroalkane- $\mathrm{CO}_{2}$ Mixtures" has been published in the Journal of Physical Chemistry, B. Our paper "Self-Assembly of Reverse Micelles with Aqueous Cores in Supercritical Carbon Dioxide via Molecular Simulation" has been accepted by Langmuir.

\subsection{STRUCTURE AND PROPERTIES OF CHAIN MOLECULE SYSTEMS UNDER SHEAR (H. D. Cochran, P. T. Cummings, S.-T. Cui, H.-J. Dai, J. D. Moore, Yu. V. Kalyuzhyi, and M. D. Dadmun)}

Contact: H. D. Cochran

Telephone: (423) 574-6821

Internet: hdc@ornl.gov

Summary: This program employs experiments, molecular simulations, and theory to understand the structure and properties of systems of long-chain molecules under homogeneous shear (planar Couette flow).

\subsubsection{Objective}

The aim of this program is to develop techniques for quantitative, molecular-based prediction of the structure and properties of systems of long-chain molecules undergoing shear flow through coarse graining of accurate, atomistic simulations of shorter-chain systems and coarse graining based on theory and verified by careful small-angle light scattering (SALS), (SAXS), and small-angle neutron scattering (SANS) experiments on sheared systems.

\subsubsection{Progress}

H. J. Dai has continued to assemble the apparatus for SALS with a cell capable of extremely high rates of shear strain. The charge-coupled device camera is on hand. The dual-cantilever slider arm for the shear cell must receive surface finish and have strain gauges mounted. The optical train must be completed with permanent mounts and optical shielding. Testing of the completed apparatus is scheduled to begin during the summer. 
Our transient shear simulations of stress overshoot in $\mathrm{C}_{100} \mathrm{H}_{202}$ at $448 \mathrm{~K}$ and $0.75 \mathrm{~g} / \mathrm{mL}$ have been shown to be in agreement with predictions of Doi-Edwards theory, despite the short chain length, if the longest molecular relaxation time (strain-rate-dependent diffusional relaxation time, measured in the simulations) is used instead of the conventional disentanglement time.

Equilibrium molecular dynamics simulations have been completed using a second nonequilibrium potential model, which is expected to yield a more accurate fluid structure at high strain rates. The results show improvement over those of the previous model but are still poor. Theoretical development of a better nonequilibrium potential is needed.

Our paper "Molecular Dynamics Simulation of the Rheological and Dynamical Properties of a Model Alkane Fluid Under Confinement" has been published in the Journal of Chemical Physics.

Our paper "Distribution Functions of a Simple Fluid Under Shear" has been accepted by Physical Review E. Our paper "The Transient Rheology of a Polyethylene Melt Under Shear" has been submitted to Physical Review E.

\subsection{PUBLICATIONS}

\subsubsection{Submitted}

J. D. Moore, S. T. Cui, H. D. Cochran, and P. T. Cummings, "The Transient Rheology of a Polyethylene Melt Under Shear," Phys. Rev. E (1999).

\subsubsection{Accepted}

Y. B. Melnichenko, E. Kiran, G. D. Wignall, K. D. Heath, S. Salaniwal, H. D. Cochran, and M. Stamm, "Pressure and Temperature-Induced Transitions in Polymer Solutions in Supercritical Fluids," Macromolecules (1999).

Yu. V. Kalyuzhnyi, S. T. Cui, P. T. Cummings, and H. D. Cochran, "Distribution Functions of a Simple Fluid Under Shear," Phys. Rev. E 60 (1999).

Y. B. Melnichenko, E. Kiran, K. Heath, S. Salaniwal, H. D. Cochran, M. Stamm, W. A. Van Hook, and G. D. Wignall, "SANS Studies of Polymers in Organic Solvents and Supercritical Fluids in Poor, Theta, and Good Solvent Domains," ACS Symp. Ser. (1999).

S. Salaniwal, S. T. Cui, P. T. Cummings, and H. D. Cochran, "Self-Assembly of Reverse Micelles with Aqueous Cores in Supercritical Carbon Dioxide via Molecular Simulation," Langmuir (1999). 


\subsubsection{Published}

S. T. Cui, P. T. Cummings, and H. D. Cochran, "Molecular Dynamics Simulation of the Rheological and Dynamical Properties of a Model Alkane Fluid Under Confinement," J. Chem. Phys. $111,1273-80$ (1999).

T. H. Walker, H. D. Cochran, G. J. Hulbert, and L. R. Wilhelm, "Supercritical Carbon Dioxide Extraction of Lipids from Pythium irregulare," J. Am. Oil Chem. Soc. 76, 595-602 (1999).

S. T. Cui, H. D. Cochran, and P. T. Cummings, "Vapor-Liquid Phase Coexistence of Alkane-CO $\mathrm{C}_{2}$ and Perfluoroalkane-CO ${ }_{2}$ Mixtures," J. Phys. Chem. B 103, 4485-91 (1999).

J. D. Londono, D. D. Wignall, H. D. Cochran, J. B. McClain, D. E. Betts, D. A. Canelas, J. M. DeSimone, E. T. Samulski, and R. Triolo, "Small Angle Neutron Scattering from Polymers in Supercritical Carbon Dioxide," Neutron News 10, 10-15 (1999).

\section{BIOTECHNOLOGY RESEARCH}

\section{E. Greenbaum}

\subsection{KINETICS OF ENZYME-CATALYZED REACTIONS (E. Greenbaum, J. Woodward, J. W. Lee, B. R. Evans, and S. L. Blankinship)}

Contact: E. Greenbaum

Telephone: (423) 574-6835

Internet: exg@ornl.gov

Summary: This research investigates the fundamental reactions of photosynthesis and the conversion of light energy into chemical energy. During the period, isotopic tracers were used to determine the enrichment of deuterium in the hydrogen/deuterium gas that was evolved during the simultaneous photoevolution of hydrogen and oxygen.

\subsubsection{Purpose and Scope}

The purpose of this research program is to study the fundamental reactions of photosynthesis and conversion of light energy into chemical energy. Sustained simultaneous photoevolution of molecular hydrogen and oxygen is studied as a model photosynthetic reaction in which the energyrich product is molecular hydrogen rather than a carbon dioxide fixation compound. Basic issues investigated include the molecular mechanisms of gas evolution, the thermodynamic limits of photosynthesis, and the mininum number of light reactions required to split water into hydrogen and oxygen. Fundamental studies on the enzymology of cellulase are also being performed. 


\subsubsection{Progress}

During the current reporting period, we performed collaborative experiments with Dr. Juske Horita of the Chemical and Analytical Sciences Division using isotope tracers to determine the enrichment of deuterium in the gas phase of hydrogen/deuterium gas that was evolved during the simultaneous photoevolution of hydrogen and oxygen. For these experiments, a $20 \%$ mixture of $\mathrm{D}_{2} \mathrm{O}$ in $\mathrm{H}_{2} \mathrm{O}$ was prepared. The results indicate that for both Chlamydomonas reinhardtii and Scenedesmus obliquus, the thermodynamic driving pressure of hydrogen production is close to the equilibrium value. This is a somewhat surprising result since the energy of the two-photon sequential light reaction of photosynthesis is more than enough to drive the reaction well beyond equilibrium. In addition to these studies, the alternate fate of reductant in Scenedesmus was studied in the presence and absence of nitrate from the assay medium. In the presence of nitrate, it was observed that the nitrate reductase pathway can account for as much as $50 \%$ of the flow of electrons toward reducing sinks in the absence of atmospheric carbon dioxide.

Using atomic force microscopy (AFM), we have demonstrated that the effects of two major cellulase components, CBH I and EG II, on the surface of cotton fibers are completely different. Treatment with CBH I caused the surface to appear abraded and gouged. Treatment with EG II appeared to cause peeling and smoothing of the fiber surface. In combination, their effect was observed to be greatest when both enzymes were present simultaneously. When fibers smoothed by treatment with EG II were subsequently treated with $\mathrm{CBH}$ I, evidence for tracking of $\mathrm{CBH} I$ along the fibers was observed. Incubation with a cellulase from Thermotoga maritima that lacks a cellulose-binding domain (CBD) caused no surface effect on the cotton linters. The images obtained provide the first physical evidence of various mechanisms of cellulase action on the surface of cotton fibers and the first AFM image of CBH I molecules.

\subsection{BIOMOLECULAR ELECTRONICS (E. Greenbaum, I. Lee, and J. W. Lee)}

Contact: E. Greenbaum

Telephone: (423) 574-6835

Internet: exg@ornl.gov

Summary: This research project is focused on the construction of molecular electronic devices from components extracted from spinach membranes. The key molecular structure is the Photosystem I reaction center, which is a molecular photovoltaic device and molecular diode. 


\subsubsection{Purpose and Scope}

This research project is focused on the development of molecular optoelectronic devices. It derives from our knowledge of the intrinsic photophysical properties of the reaction centers of photosynthesis: nanometer dimensions, picosecond response times, and the ability to generate potential differences of about $1 \mathrm{~V}$ upon absorption of a photon. The research is based on original discoveries in molecular electronics made in the Chemical Technology Division at ORNL. These include (1) first demonstration of direct electrical contact with the electron transport chain of photosynthesis, (2) photoflash deposition of metallic platinum at the site of electron emergence from the Photosystem I reaction center of photosynthesis, (3) establishment of a novel platinization "welding" technique that allows construction of two-dimensional arrays of Photosystem I reaction centers on a metal surface, and (4) first demonstration of a biomolecular diode in a single isolated photosynthetic reaction center. Taken together, these results indicate that purified reaction centers

of photosynthesis are very promising structures for the development of the next generation of optoelectronic devices.

\subsubsection{Progress}

We have completed our studies on the measurement of photovoltages from single-molecule photovoltaic devices extracted from green plants. The devices are the Photosystem I reaction centers of spinach membranes. Differential measurements were performed in the light and dark. Using the technique of Kelvin probe force microscopy, dramatic images of single Photosystem I reaction centers were obtained in the light and dark. Based on absolute calibrations, photovoltages of $1 \mathrm{~V}$ or more were measured. This value is consistent with the photon energy absorbed by the system. The energy difference between the ground state and first excited singlet state of chlorophyll is $1.8 \mathrm{eV}$. It is also consistent with the oxidation-reduction potentials that are generated by the Photosystem I reaction center.

\subsection{RENEWABLE HYDROGEN PRODUCTION BY PHOTOSYNTHETIC WATER SPLITTING (E. Greenbaum, J. W. Lee, and S. L. Blankinship)}

Contact: E. Greenbaum

Telephone: (423) 574-6835

Internet: exg@ornl.gov

Summary: This mission-oriented research and development project is focused on the production of renewable hydrogen by microalgal water splitting. 


\subsubsection{Purpose and Scope}

The purpose of this research program is the production of renewable hydrogen by photosynthetic water splitting. Experiments on the production of hydrogen and oxygen with a view toward the design and development of a real-world process system are being performed. An understanding of the limitations of the photosynthetic process, the light saturation curves, and the long-term stability and endurance of microalgae are under investigation.

\subsubsection{Progress}

Photosynthetic hydrogen $\left(\mathrm{H}_{2}\right)$ production from algae is a potential clean energy resource of tomorrow. Creation and characterization of $\mathrm{O}_{2}$-tolerant, $\mathrm{H}_{2}$-producing photosynthetic organisms are essential to the development of this clean energy system, since the use of green algae for $\mathrm{H}_{2}$ production entails with the problem of oxygen sensitivity of the hydrogenase enzyme. Hydrogenase is synthesized under anaerobic conditions and, at present, must be kept that way in order to preserve its functionality. In green algae, photoevolution of $\mathrm{H}_{2}$ and $\mathrm{O}_{2}$ occurs in the same cell. Therefore, a technology must be developed to prevent inhibition of hydrogenase activity by the photosynthetically produced oxygen.

During this reporting period, significant progress has been made in this area of the research. Two $\mathrm{O}_{2}$-tolerant, $\mathrm{H}_{2}$-producing mutants of Chlamydomonas (141F2 and 104G5) were obtained from our collaborators, Drs. Maria Ghiradi and Michael Seibert of National Renewable Energy Laboratory, who created these mutants by classic and molecular genetic techniques. These strains were grown under a light intensity of about $20 \mu \mathrm{E} \cdot \mathrm{m}^{-2} \cdot \mathrm{s}^{-1}$ in minimal-plus-acetate medium. When the cultures grew to a cell density of about $10^{6}$ cells $/ \mathrm{mL}$, the algal cells were harvested by gentle centrifugation $(3000 \mathrm{rpm})$. They were then washed and resuspensed in fresh minimal medium for $\mathrm{O}_{2}$-tolerance hydrogen-production assays. The $\mathrm{O}_{2}$-tolerance assays were performed under atmospheres of three oxygen levels-research-grade helium (purity $>99.9999 \%$, zero oxygen), $0.125 \% \mathrm{O}_{2}$ in helium, and $1.00 \% \mathrm{O}_{2}$ in helium using our unique dual-reactor-flow detection system. The $1.00 \% \mathrm{O}_{2}$ in helium was a calibration gas mixture (primary standard) purchased specially from Matheson Gas Products, Morrow, Georgia. The $0.125 \% \mathrm{O}_{2}$ in helium was created by blending $1.00 \% \mathrm{O}_{2}$ in helium with pure helium.

The results of the assays are quite encouraging. Significant $\mathrm{O}_{2}$ tolerance was demonstrated in mutants $141 \mathrm{~F} 2$ and $104 \mathrm{G} 5$ at the $0.125 \% \mathrm{O}_{2}$ level. At this level, mutants $141 \mathrm{~F} 2$ and $104 \mathrm{G} 5$ were able to photoevolve $\mathrm{H}_{2}$ for many hours at rates much higher than the wild type (137c). Although the introduction of $0.125 \% \mathrm{O}_{2}$ affected the rates of hydrogen photoevolution in all three strains, the 
decay of $\mathrm{H}_{2}$ production was much less in $141 \mathrm{~F} 2$ and $104 \mathrm{G} 5$ than in $137 \mathrm{c}$. The steady-state rates of hydrogen photoevolution in 141F2 and 104G5 were retained at about 75 and $50 \%$ of their original rates before the introduction of $0.125 \% \mathrm{O}_{2}$, while the wild type retained less than $20 \%$ of its original $\mathrm{H}_{2}$ photoevolution rate. This is an important result, since it demonstrates the first human-engineered progress toward $\mathrm{O}_{2}$ tolerance in algal $\mathrm{H}_{2}$ production.

More research effort for improvement of $\mathrm{O}_{2}$ tolerance is needed. Neither $141 \mathrm{~F} 2$ nor $104 \mathrm{G} 5$ was capable of tolerating higher levels of $\mathrm{O}_{2}$. Introduction of $1 \% \mathrm{O}_{2}$ in helium resulted in complete inhibition of $\mathrm{H}_{2}$ photoevolution in both mutant 141F2 and the wild type, 137c. Within about $10 \mathrm{~min}$ after the carrier gas was shifted from $1 \% \mathrm{O}_{2}$ in helium to pure helium (zero oxygen), photoevolution of $\mathrm{H}_{2}$ started to recover in both the mutant and the wild type. However, the recovery of $\mathrm{H}_{2}$ photoevolution in mutant 141F2 was significantly faster than that in the wild type. These results indicate that the oxygen inhibition of $\mathrm{H}_{2}$ photoevolution is reversible and that the mutation in 141F2 apparently makes this reversible recovery occur faster. Similar results were observed in comparative studies between mutant 104G5 and wild-type 137c.

\subsection{FLUOROMETRIC TISSUE-BASED BIOSENSORS (E. Greenbaum and C. A. Woodward)}

Contact: E. Greenbaum

Telephone: (423) 574-6835

Internet: exg@ornl.gov

Summary: The objective of this research program is the utilization of microalgae as biosensors for the detection of environmental toxins.

\subsubsection{Purpose and Scope}

The purpose and scope of this research project is the development of rapid fluorometric assays for environmental toxins, including chemical and biological warfare agents. It is based on the well-known fact that any interference with the electron transport chain of photosynthesis gives rise to an increase in the quantum yield of fluorescence. Moreover, the availability of relatively inexpensive commercial instrumentation makes this approach to biological-and chemical-warfare detection a practical possibility.

\subsubsection{Progress}

Ongoing experiments in the laboratory form the basis for the development of fluorometric techniques to detect the presence of chemical toxins that may pose a threat to human health. The 
objective of the work is to develop a mobile, rapid, and sensitive biosensor composed of photosynthetic tissues and to assess the fundamental interactions of chemical toxins with the sensor by measuring fluorescence. The fluorometric signature can be directly related to the physical-well being of the tissue during exposure to low concentrations of specific toxic agents. In initial experiments, the eukaryotic alga Chlorella was grown in minimal-medium liquid culture and immobilized onto fiberglass filter-paper supports. Its fluorescence patterns were measured by using an OS-30 handheld chlorophyll fluorometer from Opti-Sciences, Inc. Fluorescence patterns following exposure of Chlorella to aqueous solutions of potassium cyanide $(\mathrm{KCN})$ and to vapors from the vesicant simulants dibutyl sulfide (DBS) and tributylamine (TBA) showed characteristic changes in the fluorescence curves corresponding to dose and length of exposure. The organism used for the biosensor will use $\mathrm{CO}_{2}$ as its only carbon source (as Chlorella does) but will also have to withstand extended periods of low-water stress. The cyanobacteria Nostoc commune, which is known to be resistant to anhydrous conditions in its natural environment, is also being grown in the laboratory in liquid culture and has been immobilized on fiberglass filters. Fluorescence-characteristic curves have been recorded and, at present, are being tested for fluorescence sensitivity to KCN, DBS, and TBA. $N$. commune's viability after exposure to low-water conditions can be tested by measuring $\mathrm{CO}_{2}$ consumption. (Uptake of $\mathrm{CO}_{2}$ is an indicator of the presence of photosynthetic activity in organisms.) A closed system, consisting of a gastight apparatus with an in-line LI-COR $\mathrm{CO}_{2}$ analyzer has been set up and will be used to monitor the decrease in respiration during desiccation and the resumption of respiration and photosynthesis after rehydration. The objectives are to determine the long-term stability of algae and cyanobacteria, which are highly sensitive to toxic chemical agents, and to optimize the fluorescence response for early warning of potential chemical hazards.

\subsection{CELLULASES WITH ENHANCED ACTIVITY (B. R. Evans, J. Woodward, and I. Hemery)}

Contact: J. Woodward

Telephone: (423) 574-6826

Internet: oop@ornl.gov

Summary: A thermophilic endoglucanase with high activity on soluble cellulose and two different $\mathrm{CBDs}$ were incubated with insoluble cellulose to determine if the endoglucanase would be able to bind to and hydrolyze insoluble cellulose by synergistic interaction with the CBDs. No hydrolysis of the insoluble cellulose was observed, indicating that presence of the CBDs in the reaction was not sufficient to impart activity to the endoglucanase. 


\subsubsection{Purpose and Scope}

To improve biocatalysts for industrial conversion of lignocellulosic materials into fermentable sugars, an increase in the catalytic rate of hydrolysis of cellulose is targeted. The mechanisms of cellulase action on cellulose fibers and synergy between cellulases are still unclear. To resolve these problems, cellulases from both mesophilic and extremophilic microorganisms are being studied and their interactions with insoluble cellulose and cellulose fibers examined.

\subsubsection{Progress}

To construct a small oxidoreductase that binds to cellulose, a recombinant CBD from the Cellulomonas fimi endoglucanase CenA was expressed and purified. An eight-amino acid heme peptide, $\mathrm{mp} 8$, was covalently linked to the purified recombinant CenA CBD using water-soluble carbodiimide. The CBD was also shown to complex ferrous ion, probably by means of the eight histidine residues (His-tag) present in the Novagen expression vector. Attempts to purify a unique $\beta$-glucosidase from an Arctic psychrophile are continuing. The enzyme appears to lose activity when lysis and purification steps are carried out in HEPES or phosphate buffer. Preliminary tests of buffer compatibility indicate that TRIS buffer is preferable for purification of this enzyme. The $\beta$ fructofuranosidase from the same psychrophilic strain was induced and purified using DEAE Sepharose and HEPES buffer to a specific activity of $5.6 \mu \mathrm{mol} \cdot(\mathrm{mg} \text { protein })^{-1} \cdot \mathrm{min}^{-1}$.

\subsection{DEVELOPMENT OF A FUEL CELL (H. M. O'Neill and J. Woodward)}

Contact: J. Woodward

Telephone: (423) 574-6826

Internet: oop@ornl.gov.

Summary: Work is currently focused on methods to increase the efficiency of the enzymatic production of hydrogen from glucose.

\subsubsection{Purpose and Scope}

The future use of hydrogen as a renewable fuel is receiving wide attention in both political and technical circles. An enzymatic in vitro process for the production of hydrogen from biomass is currently under investigation. This process centers on two $\mathrm{NADP}^{+}$-dependent enzymes, glucose dehydrogenase (GDH) from Thermoplasma acidophilum and hydrogenase from Pyrococcus furious. 


\subsubsection{Progress}

Work is currently focused on the characterization of this enzymatic pathway and the immobilization of the cofactor. As detailed previously, two enzymes are required to convert glucose to hydrogen - Thermosplasma acidophilum GDH and Pyrococcus furious hydrogenase. The transfer of reducing equivalents between these enzymes is carried out by nicotinamide adenine dinucleotide phosphate $\left(\mathrm{NADP}^{+}\right)$.

In previous work, it was shown that the yield of $\mathrm{H}_{2}$ decreases as the concentration of glucose in the reaction is increased and that $\mathrm{NADP}^{+}$is unstable under the reaction conditions used. It was, therefore, of interest to determine the factors that affect the yield of $\mathrm{H}_{2}$. In the first instance, several experiments were carried out to determine the optimal ratio of GDH to hydrogenase. Therefore, the rate of $\mathrm{H}_{2}$ production depends solely on the amount of $\mathrm{GDH}$ present. The amount of $\mathrm{NADP}^{+}$was varied between 0.5 and $2 \mathrm{~m} M$ under these conditions. A plot of the maximal rate of $\mathrm{H}_{2}$ evolution versus $\mathrm{NADP}^{+}$concentration shows a hyperbolic dependence. $\mathrm{NADP}^{+}$at $\sim 200 \mathrm{M}$ gives the maximal rate of $\mathrm{H}_{2}$ production. This corresponds to the calculated $\mathrm{K}_{\mathrm{m}}$ of NADPH for hydrogenase (200 M), as determined previously. There was no evidence that higher concentrations of $\mathrm{NADP}^{+}$inhibit $\mathrm{H}_{2}$ production over the concentration range used. This is contrary to preliminary results obtained with the Solfolobus solfataricus GDH enzyme. The effect of varying the glucose concentration between 5 and $100 \mathrm{~m} M$ was also investigated. A plot of the maximal rate of $\mathrm{H}_{2}$ evolution versus the concentration of glucose shows a hyperbolic dependence. The optimum concentration of glucose is $\sim 12.5 \mathrm{mM}$. The yield of $\mathrm{H}_{2}$ does not increase significantly with glucose concentrations above $25 \mathrm{mM}$. This may suggest that inhibition of GDH occurs at high concentrations of glucose. However, as previously reported, $\mathrm{NADP}^{+}$is unstable under the reaction conditions used. This will also contribute to the drop in the yield.

The immobilization of $\mathrm{NADP}^{+}$on soluble polymers is also being investigated. As reported previously, $\mathrm{NADP}^{+}$has been immobilized on 300-KDa poly-L-lysine (PLL). Similar results have also been obtained with 27-KDa PLL. Both immobilized cofactors are active in the $\mathrm{GDH} /$ hydrogenasecoupled assay. The exact mechanism of attachment of the cofactor to PLL is being studied. Ionic interactions play a major role, but covalent attachment also occurs. $\mathrm{NADP}^{+}$was also cross-linked with derivatives of polyethylene glycol (PEG), 5000 mol.wt. The first derivative has an epoxide linker. It reacted slowly with $\mathrm{NADP}^{+}$. The preliminary results show that the largest quantity of $\mathrm{NADP}^{+}$was cross-linked after approximately 4 days when the reaction is carried out at room temperature. The second PEG derivative has a trisyl functional group. The reaction with $\mathrm{NADP}^{+}$ proceeded at a faster rate than with the epoxide derivative and appeared to be complete after 
approximately $3 \mathrm{~h}$. However, a large proportion of the $\mathrm{NADP}^{+}$could not be accounted for at the end of the reaction. It is possible that the $\mathrm{NADP}^{+}$was inactivated during the course of the reaction. The optimal reaction conditions will be investigated further. The large-molecular-weight derivatives will be used in a continuous-flow bioreactor. This will allow the reaction products to be removed and substrate to be introduced.

The hydrogen production in psychrophilic bacteria that were isolated from marine sediments is under investigation. Presently, the optimal conditions for the growth of the bacteria are being investigated. Bacterial growth has been demonstrated under aerobic and anaerobic conditions. Hydrogen is produced only under anaerobic conditions. The rates of cell growth and hydrogen production are being measured simultaneously. This is being carried out to determine the optimal conditions for hydrogen production by the bacteria. So far, hydrogen evolution has been detected only in cultures that have reached the stationary phase of growth.

The immobilization of invertase by entrapment in propylene glycol alginate gel spheres has a number of advantages. This method allows multiple dehydration/rehydration cycles of the beads without loss in enzyme activity. The beads are thermostable and are also maintenance free. However, experiments have shown that glutaraldehyde (the cross-linking agent) causes a significant loss in the activity of the enzyme during the immobilization process. Several other chemicals have been tried, including some amine-reactive homobifunctional agents and polyethyleneimine. None of these reagents have been successful to date. Investigations will continue to optimize this method for the immobilization of invertase.

\subsection{HYDROGEN PRODUCTION FROM RENEWABLES (J.P. Getty and J. Woodward)}

Contact: J. Woodward

Telephone: (423) 574-6826

Internet: oop@ornl.gov

Summary: Research has focused on the nonenzymatic production of hydrogen, specifically the optimization of hydrogen generation by an iron-powder catalyst under anaerobic conditions.

\subsubsection{Purpose and Scope}

The intent of this project is to identify a system of hydrogen generation for commercial vehicle transportation. 


\subsubsection{Progress}

We have demonstrated that gluconic acid is consumed during the reaction between iron and water in the presence of the acid. The role of gluconic acid is the reduction of magnetite $\left(\mathrm{Fe}_{3} \mathrm{O}_{4}\right)$ to metallic iron. Evidence for this comes from studies by Haruyama and Masarnura and Mancey et al., who show the dissolution of magnetite in perchlorate solutions at different potentials. Data suggest that the reduction of magnetite to iron can occur at potentials $<0.5 \mathrm{~V}$. Hydrogen evolution accompanies the magnetite dissolution reaction. An invention disclosure has been prepared.

\subsection{PUBLICATIONS}

I. Lee, J. W. Lee, A. Stubna, and E. Greenbaum, "Single-Molecule Photovoltaic Devices Extracted from Green Plants" (submitted).

B. R. Evans and J. Woodward, "Protein Injury Protection by Antioxidants," in Biomolecular Injury Causes and Prevention of Toxicity, John Wiley and Sons, New York (in press).

I. Lee, B. R. Evans, and J. Woodward, "The Mechanism of Cellulase Action on Cotton Fibers: Evidence from Atomic Force Microscopy," Ultramicroscopy (submitted).

J. Woodward, M. Orr, K. Cordray, and E. Greenbaum, "Efficient Production of Biohydrogen from Glucose-6-Phosphate," Nature (submitted).

J. Woodward, K. A. Cordray, R. J. Edmonston, M. Blanco-Rivera, S. M. Mattingly, and B. R. Evans, "Enzymatic Hydrogen Production: Conversion of Renewable Resources for Energy Production," Energy and Fuels (submitted).

\subsection{PRESENTATIONS}

E. Greenbaum, "Artificial Photosynthesis," invited lecture presented to the Defense Sciences Research Council, Defense Advanced Research Projects Agency, Arlington, Virginia, May 19, 1999.

E. Greenbaum, "Renewable Hydrogen and Oxygen Production by Photosynthesis," plenary lecture presented to the Gordon Research Conference on Fuel Cells, Plymouth, New Hamphire, June 27-July 2, 1999.

I. Lee, J. W.'Lee, and E. Greenbaum, "Biomolecular Electron Devices with Photosystem I Reaction Centers," 57th Device Research Conference, Santa Barbara, California, June 28-30, 1999.

J. Woodward, "Development of a Fermentative Process for Novel Products for the Prevention of Food Contamination," presented in honor and celebration of the jubilee of S. Satpayev, first president and founder of the Academy of Sciences, Republic of Kazakhstan, UNESCO Headquaters, Paris, France, April 1999. 
B. R. Evans, T. L. Poole, J. S. Griffiths, J. Zhou, and J.Woodward, "Extremophilic Enzymes for Utilization of Sugars," presented at the 21st Symposium on Biotechnology for Fuels and Chemicals, Fort Collins, Colorado, May 2-6, 1999.

H. M. O'Neill and J. Woodward, "The Enzymatic Conversion of Sugar to Hydrogen Stability Studies," presented at the 21 st Symposium on Biotechnology for Fuels and Chemicals, Fort Collins, Colorado, May 2-6, 1999.

\title{
8. MOLECULAR STUDIES
}

\author{
P. T. Cummings
} 8.1 AQUEOUS ELECTROLYTE SOLUTIONS AT AMBIENT AND SUPERCRITICAL
CONDITIONS (P. T. Cummings, A. A. Chialvo, M. Predota, and E. Yezdimer)

Contact: P. T. Cummings

Telephone: (423) 241-4779

Internet:u53@ornl.gov

Summary: Simulations of supercooled water were performed and the temperature measured in different ways to probe nonergodicity. Gibbs-Duhem simulations of phase equilibrium in a polarizable model of water were completed; a Gibbs ensemble code was initiated for polarizable models of water.

\subsubsection{Purpose and Scope}

This project is aimed at developing microscopic-level understanding of aqueous electrolyte solutions using a combination of molecular simulation, statistical mechanical theory, and experimental measurement of vapor-liquid equilibrium and solution densities. The state conditions of interest range from ambient conditions to high-temperature/high-pressure supercritical conditions (such as those encountered in power plant steam cycles and supercritical water oxidation).

\subsubsection{Progress}

Ariel Chialvo developed a methodology to assess the configurational temperature associated with translational as well as rotational degrees of freedom. He analyzed the behavior of the configurational (translational and rotational) temperature in comparison with the corresponding kinetic temperature for supercooled water in the range of 75 to $150 \mathrm{~K}$, as part of an ongoing collaboration with P. G. Kusalik at Dalhousie University (Canada).

Eric Yezdimer completed Gibbs-Duhem molecular simulations of the vapor-liquid equilibrium of the TIP4P-FQ fluctuating charge model for water. The phase envelope was found to disagree substantially with the experiment. Ab initio studies of the effect of water dimer geometry 
on the dipole moment were continued. Calculations of the free energy of solvation for a series of aqueous alkanes were begun, employing a relatively new method for performing the alkane insertion.

A new postdoctoral researcher, Milan Predota, joined the group. He began writing a Gibbs ensemble Monte Carlo code for calculation of vapor-liquid equilibrium of polarizable water models.

\subsection{THEORY AND MOLECULAR SIMULATION OF NONEQUILIBRIUM SYSTEMS (P. T. Cummings, A. Baranyai, S. T. Cui, J. D. Moore, I. Borzsák, and C. McCabe) \\ Contact: P. T. Cummings \\ Telephone: (423) 241-4779 \\ Internet: u53@ornl.gov}

Summary: A large-scale simulation of a model short-chain polyethylene $\left(\mathrm{C}_{100}\right)$ melt was continued, with emphasis on calculating transient rheological properties. A transient time correlation function (TTCF) formalism code, under development in our group for some time, was finally completed and validated.

\subsubsection{Purpose and Scope}

In this project, we study and develop new simulation algorithms for systems away from equilibrium. These algorithms form the basis for the calculation of transport properties using nonequilibrium molecular dynamics.

\subsubsection{Progress}

Jonathan Moore continued work on rheology of chain molecules under shear, focusing primarily on the transient and steady-state behavior of a model short-chain polyethylene $\left(C_{100}\right)$ melt.

István Borzsák found and removed an error in his TTCF code for simple fluids. The error was slightly distorting the results. The TTCF method now yields good results over the entire range of strain rates for this simple fluid. The TTCF code was used to generate results for presentation at a July conference in Granada, Spain. In addition, the parallel version of the code for $n$-decane was readied for production runs.

Clare McCabe initiated production runs for calculating the viscosity of trioctylmethane at ambient and very high (approximately gigapascal-level)) pressure.

\subsection{INTEGRAL EQUATION THEORIES OF MOLECULAR FLUIDS (P. T. Cummings, Yu. V. Kalyuzhnyi, and J. N. Herrera) \\ Contact: P. T. Cummings \\ Telephone: (423) 241-4779 \\ Internet: u53@ornl.gov}


Summary: No progress was made on this project during the current quarter.

\title{
8.3.1 Purpose and Scope
}

This project involves the use of integral equation methods to describe molecular fluids and polymers in the dense-liquid regime. The emphasis is on analytically solvable integral equation theories.

\subsubsection{Progress}

No progress was made on this project during the current quarter.

\subsection{MATHEMATICAL MODELING OF BACTERIAL MIGRATION THROUGH POROUS MEDIA WITH APPLICATION TO IN SITU BIOREMEDIATION (P. T. Cummings, R. M. Ford, K. C. Chen, and M. Jin")}

\author{
Contact: Peter T. Cummings \\ Telephone: (423) 241-4779 \\ Internet: u53@ornl.gov
}

Summary: No progress was made on this project during the current quarter.

\subsubsection{Purpose and Scope}

This project is part of a broad effort at the University of Virginia funded by the IBM Environmental Research Program, with Roseanne Ford and Peter Cummings as coprincipal investigators. The goal of the project is to perform experimental studies and computer simulations of bacterial motion in bulk aqueous phases and in porous media to develop an understanding of the transport processes involved with in situ bioremediation and to subsequently develop mathematical models for these processes. The project funding ended December 31, 1997.

\subsubsection{Progress}

This project is no longer funded and is being concluded. A final report to the sponsors (IBM) was completed and submitted in October 1998. One manuscript remains outstanding.

\footnotetext{
${ }^{*}$ University of Virginia.
} 


\subsection{FUNDAMENTAL CHEMISTRY AND THERMODYNAMICS OF HYDRO- THERMAL OXIDATION PROCESSES (J. M. Simonson, R. E. Mesmer, D. J. Wesolowksi, P. T. Cummings, and A. A. Chialvo)}

Contact: P. T. Cummings

Telephone: (423) 241-4779

Internet: u53@ornl.gov

Summary: The Chialvo-Cummings solvation formalism was applied to electrolyte solutions. Molecular simulation of $\mathrm{HCl}$ solutions was continued.

\subsubsection{Purpose and Scope}

The goal of the project is to use a combination of molecular theory/simulation and experimental measurements to develop a fundamental understanding of the thermophysical properties, phase equilibrium, and reaction processes involved in supercritical water oxidation (a new and promising technique for transforming hazardous organic waste).

\subsubsection{Progress}

Ariel Chialvo continued integral equation calculations of infinitely dilute alkali halides in a wider range of temperatures and molecular asymmetries to test a regression hypothesis currently used by experimentalists. A portion of this work will be presented at the 4th Liquid Matter Conference (Spain, July 1999) and is contained in a manuscript in preparation for the Journal of Physics: Condensed Matter. During this quarter, there was no publication or presentation activity related to this project.

\subsection{DEVELOPMENT AND APPLICATION OF FAST COMPUTATIONAL PROTEIN- FOLDING ALGORITHMS USING MASSIVELY PARALLEL SUPERCOMPUTERS (P. T. Cummings, P. H. LoCascio, K. Dill, and K. Yue*)}

Contact: P. T. Cummings

Telephone: (423) 241-4779

Internet: u53@ornl.gov

Summary: Production runs were performed using our parallelized Geocore algorithm. A preproposal to the DOE Office of Biological and Environmental Research was submitted and approved.

\footnotetext{
"University of California-San Francisco.
} 


\subsubsection{Purpose and Scope}

The goal of the project is to develop parallel implementations of the Geocore ab initio exhaustive-search protein-folding algorithm and use the parallel version to predict the structures of larger proteins, to improve the performance of the Geocore algorithm, and to develop much faster, less exhaustive algorithms for very large proteins.

\subsubsection{Progress}

Phil LoCascio conducted production runs with the parallelized Geocore ab initio proteinfolding algorithm.

A preproposal was prepared and submitted to the DOE Office of Biological and Environmental Research in response to solicitation LAB 99-19, Computational Structural Biology. The preproposal was successful.

8.7 MOLECULAR-BASED STUDY OF REVERSE MICELLES IN SUPERCRITICAL CARBON DIOXIDE FOR SOLVENT SUBSTITUTION IN THE U.S. CHEMICAL INDUSTRY (P. T. Cummings, H. D. Cochran, S. T. Cui, S. Salaniwal, G. Wignall, A. Habenschuss, E. Beckman, and J. deSimone')

Contact: P. T. Cummings

Telephone: (423) 241-4779

Internet: u53@ornl.gov

Summary: Production runs of our simulation code for reverse micelles were continued for a large-size system (five times larger than our previous simulations) and analyzed according to the Smoluchowski theory of aggregation dynamics.

\subsubsection{Purpose and Scope}

The aim of this project is to use SAXS and SANS scattering plus complementary molecular dynamics and Monte Carlo simulations to develop a molecular-level understanding of the formation and stability of reverse micelles in supercritical $\mathrm{CO}_{2}$. The results of this project will contribute to the fundamental knowledge base enabling the U.S. chemical industry to substitute supercritical $\mathrm{CO}_{2}$ for many of the toxic or hazardous solvents presently used in most industrial chemical reaction and separation processes. The project is funded by the National Science Foundation and the U.S. Environmental Protection Agency.

\footnotetext{
*University of Pittsburgh.

${ }^{\dagger}$ University of North Carolina.
} 


\subsubsection{Progress}

Sumeet Salaniwal performed production runs of our parallelized code for simulating water/surfactant/ $\mathrm{CO}_{2}$ systems for a large system that mimics the experimental conditions starting from two different initial configurations (ordered and scattered).

He also investigated by simulation the effect of surfactant chemistry on aggregation dynamics and structure. He compared the simulation results with the Smoluchowski theory of aggregation dynamics.

\subsection{NANOTECHNOLOGY WTH EMPHASIS ON TRIBOLOGY: A COMBINED EXPERIMENTAL AND SIMULATION STUDY (P. T. Cummings, H. D. Cochran, S. T. Cui, C. McCabe, S. Granick, ${ }^{*}$ and G. Grest ${ }^{\dagger}$ )}

Contact: P. T. Cummings

Telephone: (423) 241-4779

Internet: u53@ornl.gov

Summary: Molecular simulations of perfluoroalkane systems were initiated. Molecular dynamics simulations of alkanes confined to nanoscale gaps were continued.

\subsubsection{Purpose and Scope}

The aim of the project, supported by the National Science Foundation through the interdisciplinary nanotechnology program, is to undertake a fundamental study of lubrication at nanometer scale, including experiments with surface rheometry and nonequilibrium molecular dynamics simulation. The goals of the research are to achieve overlap in shear rate between experiments and simulations with the same systems; to extend both the experimental and computational efforts to more complicated systems and surface characteristics (including surfaces with chemical and topographical heterogeneity); and to study not only the steady-state shear response of nanotribology systems but also their transient behavior, including the technologically important issues related to adhesion.

\subsubsection{Progress}

Clare McCabe modified an existing code for alkanes to simulate the rheology of perfluorobutane using the potential model of Cui et al. She obtained perfluoroalkane data from the DIPRR database and chose at state point to begin production runs $\left(200 \mathrm{~K}, 1.82 \mathrm{~g} / \mathrm{cm}^{3}\right)$. The equilibrium

\footnotetext{
${ }^{*}$ University of Illinois.

${ }^{\dagger}$ Sandia National Laboratory.
} 
perfluorobutane results will be used to compare with neutron scattering, hence testing the validity of the potential model. The perfluoroalkane simulations mark the first step towards simulation of perfluoropolyether lubricants.

Shengting Cui completed molecular dynamics simulations of alkane liquids confined to nanoscale gaps between surfaces that mimicked the properties of mica. His simulations are unique in that the mica surfaces are pulled at a constant force and the stick-slip behavior induced is then converted to a relative velocity of the surfaces.

\subsection{OTHER IMPORTANT ACTIVITIES}

Peter Cummings received a 1999 Lockheed Martin research achievement award, recognizing sustained research achievement. From June 5-July 1, 1999, Cummings was a visiting professor in the Department of Chemical Engineering at Universitat Rovira I Virgili, Tarragona, Spain. The purpose of the visit was to establish a research collaboration with the molecular simulation group at this university.

\subsection{PUBLICATIONS}

\subsubsection{Submitted}

E. J. M. Filipe, E. J. S. Gomes de Azevedo, L. F. G. Martins, V. A. M. Soares, J. C. G. Calado, C. McCabe, and G. Jackson, "Thermodynamics of Liquid Mixtures of Xenon and the Alkanes: Xenon + Ethane and Xenon + Propane,"J. Phys. Chem.

E. J. M. Filipe, L. F. G. Martins, J. C. G. Calado, C. McCabe, and G. Jackson, "Thermodynamics of Liquid Mixtures of Xenon and the Alkanes: Xenon $+n$-Butane and Xenon $+i$-Butane," $J$. Phys. Chem.

\subsubsection{Accepted}

S. Salaniwal, S. T. Cui, P. T. Cummings, and H. D. Cochran, "Self-Assembly of Reverse Micelles in Water/Surfactant/Carbon Dioxide Systems by Molecular Simulation," Langmuir (1999).

E. M. Yezdimer and P. T. Cummings, "Calculation of the Vapor-Liquid Coexistence Curve for a Fluctuating Point Charge Water Model," Molec. Phys. (1999).

S. T. Cui, P. T. Cummings, and H. D. Cochran, "Molecular Dynamics Simulation of the Rheological Properties of a Model Alkane Fluid Under Confinement," J. Chem. Phys. (1999).

T. Driesner and P. T. Cummings, "Molecular Simulation of the Temperature- and DensityDependence of Ionic Hydration in Aqueous $\mathrm{SrCl}_{2}$ Solutions Using Rigid and Flexible Water Models," J. Chem. Phys. (1999). 


\subsubsection{Published}

S. T. Cui, H. D. Cochran, and P. T. Cummings, "Vapor-Liquid Phase Coexistence of Alkane-CO ${ }_{2}$ and Perfluoroalkane- $\mathrm{CO}_{2}$ Mixtures," J. Phys. Chem. B 103, 4485-91 (1999).

\subsection{PRESENTATIONS}

\subsubsection{Invited Seminars}

P. T. Cummings, "Molecular Modeling and Simulation: New Tools for Physical Properties Prediction," presented at the Department of Chemical Engineering, University of Massachusetts, Amherst, Massachusetts, April 21, 1999.

P. T. Cummings, "Molecular Simulation of the Formation of Reversed Micelles in Supercritical Carbon Dioxide," presented at the Centre for Interfacial Science and Technology, Imperial College, London, United Kingdom, May 6, 1999.

P. T. Cummings, "Molecular Simulation of the Formation of Reversed Micelles in Supercritical Carbon Dioxide," presented at the School of Chemical Engineering, Georgia Institute of Technology, Atlanta, Georgia, May 26, 1999.

J. D. Moore, "Rheology of Chain Molecules Under Shear," presented at the Young Scientist Seminar Series, Chemical Technology Division, Oak Ridge National Laboratory, Oak Ridge, Tennessee, May 27, 1999.

P. T. Cummings, "Visualizing Complex Physical and Chemical Phenomena at the Molecular Level," presented at the Department of Chemical Engineering, Universitat Rovira I Virgili, Tarragona, Spain, June 11, 1999.

S. Salaniwal, "Reversed Micelles in Supercritical Carbon Dioxide: A Simulation Study," presented at the Department of Chemical Engineering, Imperial College, London, England, May 25, 1999.

\subsubsection{Invited Conference}

P. T. Cummings, "Molecular Simulation of Complex Systems Using Massively Parallel Supercomputers," presented at THERMODYNAMICS 99: Thermodynamics and Statistical Mechanics with Industrial Applications, London, England, April 14-16, 1999. 


\section{INTERNAL DISTRIBUTION}

1. J. M. Begovich

2. E. D. Collins

3. A. G. Croff

4. L. D. Duncan

5. R. G. Gilliland

6-61. B. J. Johnson

62. T. R. Jones

63-64. R. T. Jubin

65. J. A. Klein

66. L. E. McNeese

67. G. E. Michaels

68. B. D. Patton

69. S. M. Robinson

70. M. K. Savage

71. R. M. Wham

72. ORNL Laboratory Records-RC

73. Central Research Library

74-75. ORNL Laboratory Records-OSTI 
